\title{
A Video Decision Aid for the West Virginia POST: A Randomized, Controlled Trial
}

Jarred Vicente Gallegos

West Virginia University, jvgallegos@mix.wvu.edu

Follow this and additional works at: https://researchrepository.wvu.edu/etd

Part of the Clinical Psychology Commons

\section{Recommended Citation}

Gallegos, Jarred Vicente, "A Video Decision Aid for the West Virginia POST: A Randomized, Controlled Trial" (2020). Graduate Theses, Dissertations, and Problem Reports. 7726.

https://researchrepository.wvu.edu/etd/7726

This Dissertation is protected by copyright and/or related rights. It has been brought to you by the The Research Repository @ WVU with permission from the rights-holder(s). You are free to use this Dissertation in any way that is permitted by the copyright and related rights legislation that applies to your use. For other uses you must obtain permission from the rights-holder(s) directly, unless additional rights are indicated by a Creative Commons license in the record and/ or on the work itself. This Dissertation has been accepted for inclusion in WVU Graduate Theses, Dissertations, and Problem Reports collection by an authorized administrator of The Research Repository @ WVU.

For more information, please contact researchrepository@mail.wvu.edu. 
A Video Decision Aid for the West Virginia POST: A Randomized, Controlled Trial Jarred V Gallegos, M.A., M.S.

Dissertation submitted to the Eberly College of Arts and Sciences at West Virginia University

\author{
in partial fulfillment of the requirements for the degree of \\ $\mathrm{PhD}$ in Psychology
}

Barry Edelstein, Ph.D., Chair

Christina Duncan, Ph.D.

Kevin Larkin, Ph.D.

Aaron Metzger, Ph.D.

Alvin Moss, M.D.

Department of Psychology

Morgantown, West Virginia

2020

Keywords: End-of-life, medical decision, decision aid, POLST

Copyright 2020 Jarred V. Gallegos 


\begin{abstract}
A Video Decision Aid for the West Virginia POST: A Randomized, Controlled Trial
\end{abstract}

Jarred V Gallegos, M.A., M.S.

Patients with serious medical conditions are faced with making decisions about treatments related to end-of-life care. The Physician Orders for Life Sustaining Treatment (POLST) is a document that allows patients to express preferences for four medical decisions including cardiopulmonary resuscitation, level of medical intervention, IV fluids, and feeding tubes. Although POLST paradigm forms are used throughout the United States, there is a lack of evidence about the quality of the decision-making process of individuals completing these forms. The use of a decision aid developed for the POLST paradigm could ensure that patients completing these forms are informed, confident, and certain of their treatment decisions. The purpose of the study was to develop and evaluate a video decision aid for the West Virginia POST form. 64 English-speaking, community-dwelling adults (50+), with no evidence of cognitive impairment, were recruited to participate in the study. Participants were randomized to active control (exercise video) or intervention groups (WV POST video). Participants were provided with a clinical vignette that contained medical information for the purpose of making treatment decisions and completing measures included in the study. Participants made decisions for each of the medical decisions contained in the WV POST and completed measures of knowledge, decisional conflict, and satisfaction at pre- and post-intervention. Preliminary analyses identified problems with multicollinearity and the satisfaction variable was removed from final analyses. Separate Multivariate Analysis of Covariance (MANCOVA) analyses were conducted to examine the effect of the video aid on post-intervention ratings of knowledge and decisional conflict, while controlling for numeracy and pre-intervention ratings of decisional outcomes. Chi-Square analyses were conducted to examine the relation between treatment group and participants' decisions for medical treatments. Results identified significant main effects of treatment group for each of the four medical decisions. At post-intervention, participants in the intervention group were more knowledgeable regarding CPR, medical interventions, and IV fluids compared to participants in the control group. Additionally, participants in the intervention group had less decisional conflict related to CPR, medical interventions, IV fluids, and feeding tubes, at post-intervention compared to participants in the control group. Participants who viewed the aid were more satisfied with their CPR, medical interventions, IV fluids, and feeding tube decisions than participants who did not view the aid. There was no significant association between group and medical decision made for any of the four medical decisions in the WV POST. These findings are important because it demonstrates the individuals can be taught necessary information to make an informed decision while completing the WV POST form, and that when using a decision aid, participants feel more informed and less uncertain about their decision. The results provide foundational support for the use of decision aids with multidecision end-of-life care orders, such as POLST paradigm forms. 


\section{Table of Contents}

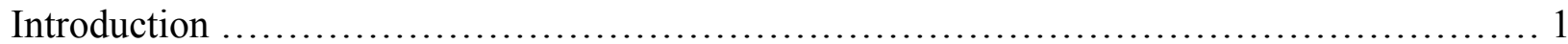

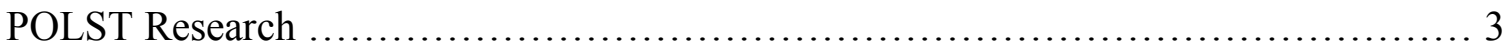

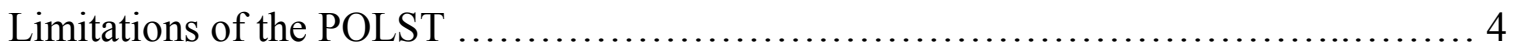

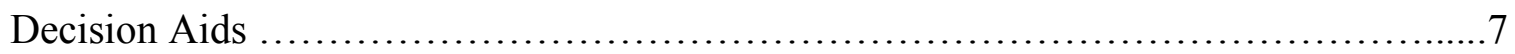

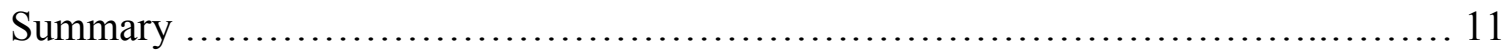

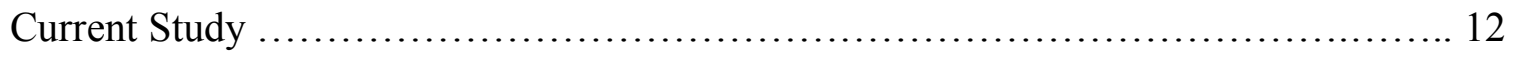

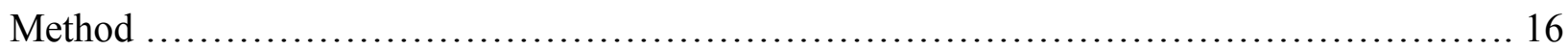

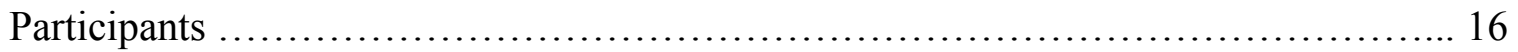

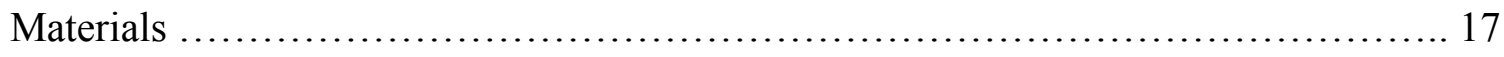

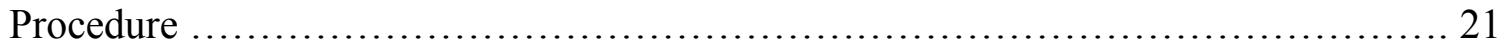

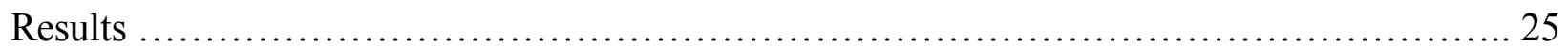

Checking Assumptions ................................................... 25

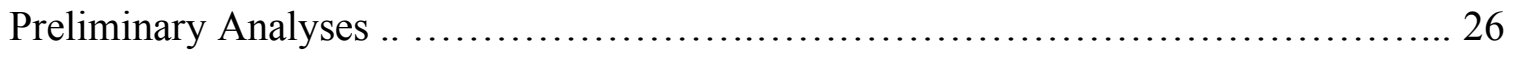

Descriptive Statistics ... ............................................... 27

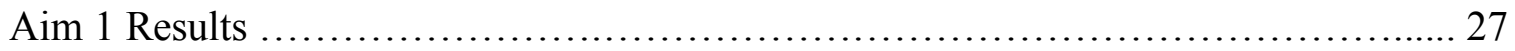

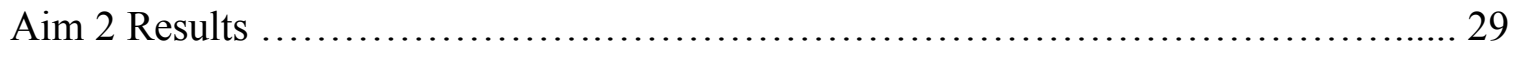

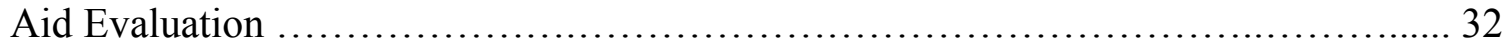

Discussion................................................................ 33

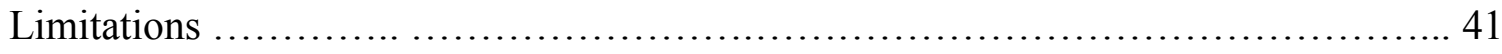

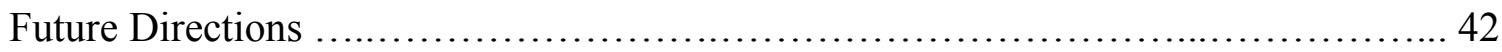

Conclusions and Implications ............................................ 43

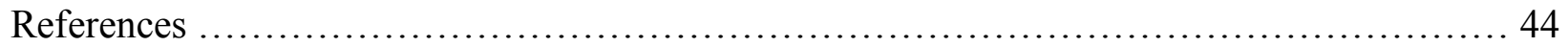


Tables........................................................................ 57

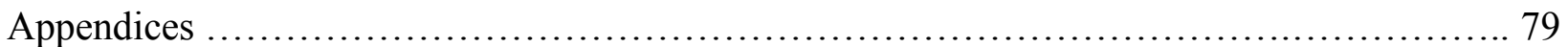


A Video Decision Aid for the West Virginia POST: A Randomized, Controlled Trial In 1991, the Physician Orders for Life Sustaining Treatment (POLST) form was created by a group of Oregon physicians to allow patients to provide preferences regarding treatments for serious medical conditions. The POLST is a legally binding medical order intended to communicate wishes for medical treatments near the end-of-life. The POLST, as it is known in many states, is also referred to as the Medical Order for Scope of Treatment (MOST), Transportable Physician Orders for Patient Preferences (TPOPP), and other state-titled variations (ex. California POLST). In West Virginia, the medical order is known as the West Virginia Physician Order for Scope of Treatment (POST). For simplicity however, "POLST paradigm" is commonly used as the umbrella term to describe the varying forms and state programs.

The National POLST is the governing body responsible for providing individual states with quality standards, guidelines for implementation, and instructions for legal and regulatory issues. States must demonstrate their program meets the National POLST standards to be recognized. Once states meet criteria for implementing a POLST program, they are classified as either "developing," "endorsed," or "mature." To date, all but five states in the U.S. have been recognized as either developing or endorsed and there are currently two states recognized as mature. POLST paradigm forms are used in a variety of clinical settings such as nursing homes (Hickman et al., 2018; Hickman et al., 2004), hospitals (Bomba \& Orem, 2015), and hospice organizations (Hickman et al., 2009).

A POLST paradigm form is a brightly colored sheet of paper that contains multiple medical treatments related to end-of-life care. Although there are slight variations of forms used across the country, the majority have three primary sections of medical treatments. These treatments are: cardiopulmonary resuscitation (CPR), medical interventions, and medically administered 
fluids and nutrition. The West Virginia POST separates these treatments into Sections A, B, and $\mathrm{C}$, respectively. In section A, the patient or appointed healthcare decision-maker, states whether the patient would want CPR performed in the event of cardiac arrest by stating a preference for resuscitation or do-not-resuscitate (DNR). In Section B, the patient states a preference for the extent of life-prolonging care desired. The options include: Full Interventions, Limited Additional Interventions, and Comfort Measures. Full Interventions would include medical treatments to extend a patient's life, including care in the Intensive Care Unit (ICU) and other life-support measures. Limited Additional Interventions includes the treatment of basic or routine medical illness such as pneumonia and/or infection but not care in ICU or the use of life-support. Comfort measures do not include any life-prolonging medical interventions but do include any medical interventions intended to increase patient comfort through the reduction of pain or discomfort. In Section C, the patient or decision-maker provides preferences for the use of IV fluids and feeding tubes, and states whether they would want these interventions for a trial period, long-term use, or not at all.

A POLST paradigm form becomes a legally binding document after signatures are obtained from the decision-maker and healthcare representative. In many states, a physician signature is required, however some states have passed legislation to allow physician assistants and advance practice nurses to sign the form (Pope \& Hexum, 2012; Vo et al., 2011). The POLST paradigm is not designed to replace existing advance directives, such as DNR cards, living wills, or medical power of attorney designations. Instead, the POLST is intended to be used only with medically frail individuals who are likely to die in the next year. The "surprise question" (Moss et al., 2008) is used to guide when a POLST should be completed. If the physician or other medical provider would not be surprised if the patient died in the next year, then the completion of a 
POLST paradigm form is recommended. The POLST paradigm is meant to be more detailed and provide clearer instructions than other advance directives for what medical treatments the individual would prefer near the end-of-life. POLST paradigm forms are stored in the medical chart and follow the patient when changing locations of care (e.g., discharge from hospital to nursing home). Many states also make POLST paradigm forms available online to allow for quick and easy access by medical providers.

\section{POLST research}

There is a growing body of literature examining the use and implementation of POLST paradigm programs throughout the country, with a surge of research in the past ten years. For example, a considerable amount of research has focused on the congruence between decisions made on POLST paradigm forms and the care received near end-of-life. Several researchers (e.g., Collier et al., 2018; Hickman et al., 2011; Lee et al., 2000; Richardson et al., 2014; Tolle et al., 1998) have reported low incidence of unwanted CPR (0\%-9\%) performed on patients who have a documented Do-Not-Resuscitate (DNR) preference. Hickman et al. (2011) found that care received was consistent with POLST paradigm orders $94 \%$ of the time in over 800 nursing home residents from Oregon, Wisconsin, and West Virginia. There is also a high congruence for patients who document preferences to receive higher levels of intervention. Richardson et al. (2014) found that patients with a documented order to attempt CPR in the completed form were more likely to receive CPR than patients without a POLST paradigm form. Additionally, Hammes et al. (2012) found that patients were more likely to receive additional treatments beyond comfort measures if it was documented in the POLST paradigm form.

Researchers have also compared outcomes between patients who complete POLST paradigm forms to outcomes of patients with other types of advance directives. Patients with a 
POLST are more likely to have orders beyond CPR (Medical interventions, IV fluids, feeding options) compared to traditional advance directives alone (Hickman et al., 2010), and are twice as likely to be admitted to hospice than patients with other advance directives (Pedraza et al., 2016). Patients with a documented preference for comfort measures in a POLST paradigm form are more likely to have an out-of-hospital death compared to patients who complete traditional advance directives (Hammes et al., 2012; Pedraza et al., 2016). The desirability of an out-ofhospital death is evident in a study of over 2500 Medicare beneficiaries (Barnato et al., 2007), which found that $86 \%$ of respondents reported a preference for spending their last days at home. Pedraza et al. (2016) found that patients with a documented preference for higher levels of medical interventions (limited and full interventions) in a POLST paradigm form were still more likely to have an out-of-hospital death than patients with other advance directives.

\section{Limitations of the POLST}

The POLST paradigm is not without limitations or areas of need for future research. Although the National POLST provides standards for POLST form components, it does not provide instructions for the completion of forms. The lack of standardization in completing POLST paradigm forms raises concerns about variability in how the POLST is completed, the extent to which patients are fully informed of risks and benefits for each decision, and the quality of the collaborative decision-making process associated with the choices made by patients when completing the POLST.

The lack of a structured discussion or sufficient guidance for completing a POLST paradigm form can lead to incomplete forms, and forms not being completed correctly. A study by Clemency et al. (2017) reviewed 100 previously completed POLST paradigm forms that accompanied patients transported to an emergency department in New York. The researchers 
found that 69 forms had at least one section of orders missing and that 14 forms had contradictory/medically incompatible orders. In another study of 938 POLST paradigm forms of nursing home residents in California, Rahman et al. (2017) found that $30 \%$ of completed forms were either missing required signatures or contained medically incompatible orders (e.g. comfort measures and hospital transfer). Additionally, the authors of the 2017 Oregon POLST online registry report stated that $23 \%$ of all forms received that year were "Not Registry Ready," due primarily to missing information in required fields. Multiple issues can arise if POLST paradigm forms are not completed correctly. One issue is that states are forced to reject or nullify forms if information is missing in required fields. Another issue pertaining to forms with incompatible orders is the increased chance of the patient receiving care that is incongruent with their wishes. A form indicating preference for DNR and full interventions is an example of a medically incompatible order, because full interventions includes the use of CPR in the event of cardiac arrest. This scenario is further complicated by the default standard of care in most states to provide all interventions to sustain life unless there is a documented order stating otherwise. A medically incompatible order creates uncertainty for the medical provider during an acute crisis where the patient is unable to communicate their preferences verbally. In this situation, if patient preferences are not clear in a POLST paradigm form, the provider will be ethically responsible to sustain life despite the fact that the documented preference was to not resuscitate.

Patients who receive incomplete or insufficient information during the completion process may not feel confident in their decisions, and thus avoid making certain treatment decisions contained in the form. This may be due to patients feeling uninformed about the nature of other treatments and the associated benefits and burdens. The lack of a thorough and detailed procedure for individuals completing POLST paradigm forms likely creates variability in what 
information is presented, when the information is shared, and how it is discussed. This variability can result in patients being unable to make a decision or making poorly informed decisions.

Another concern that stems from the lack of a standardized completion process is the potential negative influence on decision quality. If the completion process is not standardized, then patients/families completing POLST paradigm forms may receive incomplete information or may not have the opportunity to discuss the treatment choices, which could lead to less informed decisions and less confidence when making decisions. Unlike the growing research investigating the completion of POLST paradigm forms, there is relatively little research investigating the quality of the decision-making process. Hickman et al. (2017) conducted a small pilot study to investigate POLST paradigm decision quality. Participants were nursing home residents and surrogate decision-makers who had completed POLST paradigm forms in the past year. Although the majority of participants remembered completing the form, $79 \%$ of residents and $50 \%$ of surrogates reported current treatment preferences that differed from the treatment preferences contained in the completed form. Participants reported a lack of knowledge, lack of clarity concerning preferences, initial confusion, and lack of interest as factors in the resulting discrepancies. Study authors concluded that the discrepancies could be an indication of problems in the initial POLST discussion and that there may be room for improvement in the decision-making process when completing the forms with patients. Although there is limited available research investigating the quality of POLST paradigm decisions, Hickman et al. (2015) have suggested that future research examine the decision-making process and recommended the use of decision-support tools.

The POLST paradigm was developed in part, to encourage collaboration between patients, families, and medical providers about end-of-life care decisions. The process of actively 
including patients and families in healthcare decisions is central to the concept of shared decision-making (Stacey et al., 2014). Shared decision-making involves the incorporation of patient and family values with relevant medical information. The process should include the presentation of the risks and benefits for each treatment alternative and communication about what factors are most important to the patient and/or family (Makoul \& Clayman, 2006). Ideally, both the patient and provider are satisfied with the decision-making process and treatment decision made (Charles et al., 1997; Makoul \& Clayman, 2006). In a systematic review of the literature, Shay and Lafata (2015) found that patients who reported engaging in shared decisionmaking, reported lower levels of anxiety related to decision-making and more confidence in their decision than patients who reported not engaging in shared decision-making. Due to the sensitive nature and the life and death significance of end-of-life decisions, it is important to consider the content of these clinical conversations and factors that influence the shared decision-making process (Belanger, 2017). One method for ensuring the integrity of the decision-making process with the goal of informed decisions is the use of decision aids.

\section{Decision Aids}

A decision aid is an educational intervention containing information designed to assist patients or their surrogate decision-makers with medical decisions. A decision aid differs from general health education materials by making explicit the medical decision to be made and providing sufficient information for the purpose of preparing people for decision-making (Stacey et al., 2014). Common elements of decision aids are descriptions of treatment options available and the likely outcomes associated with each option. Decision aids are intended to be implemented alongside clinician/practitioner counseling, rather than serve as a replacement for this interaction (O’Connor et al., 1999). Decision aids can be presented using a variety of 
mediums such as written-handouts, audiotapes, or videos. Video aids are arguably the most effective form of a decision aid (Gillick \& Volandes, 2009), because videos can provide a more accurate representation of what to expect during certain medical procedures compared to textbased aids. Researchers have also demonstrated a high level of participant comfort when viewing decision aids that depict simulated CPR and real patients being cared for in an ICU (El-Jawahri et al., 2015; Epstein et al., 2013; Volandes et al., 2013).

Researchers have also outlined core dimensions for evaluating decision aids. The International Patient Decision Aid Standards (IPDAS) Collaboration is a collection of researchers who have recommended core components for assessing the effectiveness of a decision aid. The collaboration specified that to demonstrate an aid is effective, researchers should provide evidence that the use of the aid improves: the quality of the decision-making process and/or the quality of the choice made (Elwyn et al., 2006). Specific examples include whether a decision aid: makes clear the medical decision to be made, helps patients feel informed about the risks and benefits of treatment options, are clear about personal values, and allow patients to be involved in decision-making (Sepucha et al., 2013). The most common variables investigated to evaluate the quality of a decision aid are participant knowledge, decisional conflict, and participant satisfaction (Stacey et al., 2014). Knowledge tests are developed to assess patient understanding of key information shared in the decision aid and knowledge tests vary in length and content based on the medical decision. The Decisional Conflict Scale (O’Connor, 1994) and Satisfaction with Decision Scale (Holmes-Rovner et al., 1996) are commonly used measures in the literature. Measures to assess a decision-makers health literacy and numeracy are not commonly implemented in studies evaluating the effectiveness of a decision aid. However, these constructs can greatly influence an individual's ability to 
comprehend and weigh the presented information, therefore it is important to assess these abilities for individuals making complex medical decisions.

There is considerable evidence demonstrating the utility and effectiveness of implementing decision aids with individuals making healthcare decisions such as cancer screening, vaccines, chemotherapy treatments, etc. A large meta-analysis (Stacey et al., 2017) found that using a decision aid: increases participant knowledge about treatments and outcomes, including more accurate risk perceptions, decreases decisional conflict, specifically related to feeling informed and being clear about personal values, and increases satisfaction with the decision and the decision-making process. The review also found that the use of decision aids reduces the proportion of patients who are undecided, potentially due to patients feeling more informed after using the aid.

There is also evidence that the use of a video aid for end-of-life medical decisions is related to the medical decision made. This finding is primarily demonstrated in research studies examining the effect of using an aid on decisions for CPR and medical interventions. In a sample of patients with advanced cancer, Volandes et al. (2013) found that participants were more likely to decline CPR after seeing a video aid. Patients were also more likely to decline CPR after viewing a video aid in studies with hospital patients in intensive care units (El-Jawahri et al., 2015) and patients advanced heart failure (El-Jawahri et al., 2016). The use of a video aid has also been shown to be related to decisions for medical interventions. Patients who had watched a video aid were more likely to opt for comfort measures over full interventions compared to patients who did not see the video in studies of elderly skilled nursing facility residents (Volandes et al., 2012) and patients with advanced cancer (El-Jawahri et al., 2010). Authors of previous studies (Epstein et al., 2013; Volandes et al., 2009) have concluded that decision aids, 
particularly video aids, can most accurately portray medical treatments and associated outcomes. The belief is that being more informed about associated risks and witnessing potentially violent medical treatments such as CPR results in decisions to decline types of medical interventions that pose significant physical risks without promise of extending life.

The use of decision aids for end-of-life medical decisions is particularly relevant for the completion of a POLST paradigm form. A recent review (Cardona-Morrell et al., 2017) found that decision aids to facilitate advance care planning decisions are well-accepted by participants and result in increased knowledge and decreased decisional conflict. Participants who used decision aids to make decisions about CPR and levels of medical care have also been found to be less likely to opt for aggressive care or CPR (Einterz et al., 2014; El-Jawahri et al., 2016).

One way to ensure that patients completing POLST paradigm forms are informed and that they engage in shared decision-making, is to develop and evaluate a decision aid for the POLST. Several reviews (Cardona-Morrell et al., 2017; Jain et al., 2015; Stacey et al., 2017; van Weert et al., 2016) have found decision aids are useful for individuals making complex medical decisions such as end-of-life decisions, resulting in increased knowledge, decreased decisional conflict, and increased satisfaction with decision. Although decision aids have been created for certain advance care planning decisions, the evaluation of published aids for the POLST paradigm is limited.

At this time, only one aid specifically designed for the POLST paradigm has been evaluated. A study by Gallegos et al (2020) described the development and evaluation of a video decision aid for the medical interventions section of the West Virginia POST form. Researchers found that at post-intervention, participants had increased knowledge of treatment options and associated risks and benefits, decreased decisional conflict, and increased satisfaction with 
decision compared to pre-intervention scores. However, this study had several limitations. First, the decision aid was developed only for one decision (medical interventions) in the West Virginia POST. Second, the study had a limited experimental design, most notably the lack of a comparison group to more effectively examine the effects of the aid on primary outcomes. Third, the video utilized in the study was limited in that there was no images or video depictions of specific treatments. Lack of visual content could lead to biased or less informed decisions due to the lack of understanding of what associated treatments entail (e.g. CPR compressions, mechanical ventilation). Last, the study did not examine the effect of the aid on the choice for medical interventions, which raises questions about the potential influence of the aid.

\section{Summary}

The POLST paradigm is a medical order that contains patient wishes for treatments near the end-of-life. The form allows patients or surrogates to state their preferences for CPR, medical interventions, and medically administered fluids and nutrition. Researchers have provided evidence to support the use of the POLST paradigm. There is a high congruence between patient POLST paradigm orders and the care that they receive near the end-of-life, particularly with regards to CPR decisions. The POLST paradigm is used in the majority of states across the U.S. and is believed by staff to be helpful in a variety of ways.

Despite the benefits found in previous research, there is a dearth of evidence concerning the nature, quality, and outcomes of the decision-making process of patients completing POLST paradigm forms. The lack of a standardized process for completing the forms permits potential variability in what information is shared, and how and when it is shared. Additionally, the lack of standardization raises concerns about whether the POLST form is being completed in a thorough and thoughtful manner that includes shared decision-making. Following their review of the 
POLST paradigm literature, Hickman et al. (2015) recommended that future research investigate the quality of POLST decisions through the evaluation of decision-support tools. Decision aids improve decisional outcomes including; knowledge, conflict, and satisfaction. To date however, no published studies have evaluated a decision aid for the entire POLST. Further, there is little research about the quality of POLST paradigm decisions, other than a small sample pilot study (Hickman et al., 2017) and a study evaluating an aid for section B of the West Virginia POST (Gallegos et al., 2020).

\section{Current Study}

The purpose of the current study was to evaluate a video decision aid for the West Virginia POST form. This study sought to extend the work done by Gallegos and colleagues (2020) by improving several key aspects of the previous study. First, the current study utilized an aid with expanded medical information to allow completion of all medical decisions contained in the WV POST form. Second, the current aid was created by a professional production company in collaboration with the West Virginia University Simulation Training and Education for Patient Safety (STEPS) Center which allowed for the inclusion of realistic visual depictions of medical interventions contained in the POST. Last, the use of a comparison group (attention control), inclusion of statistical covariates to account for participant characteristics at baseline, and more purposeful sampling considerations are all methodological improvements which served to strengthen the overall design of the current study.

The current study had two aims: (1) examine the effect of a decision aid on decisional outcomes (knowledge, decisional conflict, satisfaction) for each medical decision presented in the WV POST, and (2) examine the influence of a decision aid on treatment decisions for each component of the WV POST. 


\section{Aim 1 Research Questions}

(Q1) Will the decision aid improve knowledge of CPR? (H1) Participants receiving the decision aid will have higher post-test CPR knowledge scores than the attention control group participants. This hypothesis is based on previous research (El-Jawahri et al., 2015; Volandes et al., 2013) demonstrating that the use of a decision aid increases scores of CPR knowledge.

(Q2) Will the decision aid decrease decisional conflict related to CPR? (H2) Decision aid group participants will have less decisional conflict related to the CPR decision at post-test than the attention control group participants. This hypothesis is based on a study (El-Jawahri et al., 2010) that showed a decrease in decisional conflict regarding a CPR decision after using a decision aid.

(Q3) Will the decision aid improve satisfaction with decision regarding CPR? (H3) Participants that view the decision aid will be more satisfied with the CPR decision at post-test than the attention control participants. Although no published studies have investigated whether a decision aid increases participant satisfaction with a CPR decision, decision aids have been found to increase satisfaction for other medical decisions (Stacey et al., 2017).

(Q4) Will the decision aid improve medical interventions knowledge? (H4) Participants receiving the decision aid will have higher post-test medical interventions knowledge scores than the attentional control group participants. This hypothesis is based on previous research studies (Hanson et al., 2017; Volandes et al., 2011) that found the use of a decision aid increases knowledge of medical interventions.

(Q5) Will the decision aid decrease decisional conflict related to medical interventions? (H5) Decision aid group participants will have less decisional conflict related to the medical intervention decision at post-test than the attention control group participants. This hypothesis is 
based on a study (El-Jawahri et al., 2010) that showed a decrease in decisional conflict related to medical interventions decision after using a decision aid.

(Q6) Will the decision aid increase satisfaction with decision for medical interventions? (H6) Participants that view the decision aid will be more satisfied with the medical intervention decision at post-test than the attention control participants. Although no published studies have investigated whether a decision aid increases participant satisfaction with medical interventions decision, decision aids have been found to increase satisfaction for other medical decisions (Stacey et al., 2017).

(Q7) Will the decision aid increase medically administered nutrition knowledge? (H7) Participants that view the decision aid will have higher post-test medically administered nutrition knowledge scores than the attention control group participants. This hypothesis is based on previous research (Kuraoka \& Nakayama, 2014; Mitchell, Tetroe, \& O'Connor, 2001) that found increased knowledge of artificial nutrition after using a decision aid.

(Q8) Will the decision aid decrease decisional conflict related to medically administered nutrition? (H8) Participants that view the decision aid will have less decisional conflict related to medically administered nutrition at post-test than the attention control group participants. This hypothesis is based on previous research (Kuraoka \& Nakayama, 2014; Mitchell, Tetroe, \& O'Connor, 2001) that found decreased decisional conflict about artificial nutrition after using a decision aid.

(Q9) Will the decision aid increase satisfaction with decision for medically administered nutrition? (H9) Participants that view the decision aid will be more satisfied with the medically administered nutrition decision at post-test than the attention control participants. Although no published studies have found increased satisfaction with feeding tube decisions as a result of 
using an aid, decision aids have been found to increase satisfaction for other medical decisions (Stacey et al., 2017).

(Q10) Will the decision aid increase knowledge of medically administered fluids knowledge? (H10) Participants that view the decision aid will have higher post-test medically administered fluids knowledge scores than the attentional control group participants.

(Q11) Will the decision aid decrease decisional conflict related to medically administered fluids? (H11) Participants that view the decision aid will have less decisional conflict related to the medically administered fluids decision at post-test than the attention control group participants.

(Q12) What effect will the decision aid have on participant satisfaction with decision for medically administered fluids? (H12) Participants that view the decision aid will be more satisfied with the medically administered fluids decision at post-test than the attention control participants. Although no published studies have evaluated the effects of a decision aid for medically administered fluids decisions, a large review (Stacey et al., 2017) concluded that decision aids improve knowledge, decrease decisional conflict, and increase satisfaction for medical decisions.

Aim 2 Research Questions

(Q13) Will participants who view the decision aid be more likely to choose Do-NotResuscitate than CPR? (H13) Participants who view the decision aid will be more likely choose to forgo CPR than participants who do not view the aid. This hypothesis is based on multiple studies (e.g., El-Jawahri et al., 2016; Epstein et al., 2013) demonstrating that participants are less likely to opt for CPR after viewing a decision aid. 
(Q14) Will participants be more likely to choose less aggressive care than full interventions after viewing a decision aid? (H14) Participants that view the decision aid will be more likely to choose less aggressive care than participants who do not view the aid. This hypothesis is based on previous research (El-Jawahri et al., 2016; Volandes et al., 2009), that found participants were more likely to choose comfort measures than full interventions after viewing an aid.

(Q15) Will participants that view the decision aid be more likely to decline than accept IV fluids? (Q16) Will participants that view the decision aid be more likely to decline than accept medically administered nutrition? Questions 15 and 16 are exploratory research questions because there are no published studies examining whether viewing a decision aid is related to a treatment decision about either medically administered fluids or nutrition. Therefore, there are no study hypotheses for these questions.

\section{Method}

\section{Participants}

A power analysis using G*Power 3.1.9 (Faul, Erdfelder, Buchner, \& Lang, 2013) was conducted to determine the sample size required for the study. The sample size for a repeated measures MANOVA with both within- and between-group comparisons was determined for an effect size of $f$ of $0.40, a=.05$, and power $=0.80$. The effect size used in the power analysis is based on previous studies evaluating decision aids (Laupacis et al., 2006; O'Conner et al., 1999). The power analysis indicated that a sample size of 64 participants was sufficient to detect significant differences. Participants were community-dwelling adults, recruited from the greater Morgantown, WV area using advertisements (ENEWS, newspaper advertisements, etc.). Community-dwelling adults were chosen as the participant sample in efforts to limit serious 
health conditions as a potential confound. Specific inclusion criteria requirements were being English-speaking and being 50 years of age or older. Participants were excluded if they had a terminal illness or a prognosis of less than one year to live. Participants with significant cognitive impairment, as evidence by a score of $<8$ on the Montreal Cognitive Assessment (MoCA) 5minute protocol cognitive impairment screening tool. Due to potential learning effects, participants were also excluded if they took part in the related study by Gallegos et al. (2020).

\section{Materials}

Demographics. A demographics questionnaire will include the following variables: age, sex, ethnicity, years of education, marital status, chronic illness, previous medical procedures, and existing advance directives.

Video Aid. The reviewed the medical literature and scientific publications to obtain upto-date information about the risks and benefits of the medical treatment options contained in the WV POST. A script was developed to include information about the West Virginia POST sections A, B, and C. Aid content was revised with input from the physician director of the West Virginia POST program and a board-certified physician in hospice and palliative medicine. The development of the aid was guided by recommendations made by the International Patient Decision Aids Standards (IPDAS) Collaboration (Joseph-Williams et al., 2014). The current aid meets all six IPDAS qualifying criteria, including the essential components to be recognized as a decision aid. The final aid script had a Flesch Reading Ease score of 56.7 and was written at a $9^{\text {th }}$ grade Flesch-Kincaid reading level. The video aid was created by a professional production company using the aid script. The visual content for the video was filmed in a medical simulation and training center (West Virginia University Center for Simulation Training and Education for Patient Safety). 
Montreal Cognitive Assessment (MoCA) 5-minute protocol. Developed as a shortened version of the MoCA (Nasreddine et al., 2005), the MoCA 5-min protocol (Hachinski et al., 2006) is a brief four-item screening measure to detect cognitive impairment. The measure assesses several cognitive domains including; attention, executive functioning, language, orientation, and memory. Scores range from 0 to 12 , with lower scores suggesting potentially greater cognitive impairment. Using a score cutoff of 8, the MoCA 5-minute protocol has sensitivity of $85 \%$ specificity of $88 \%$ for detecting cognitive impairment in a sample of patients with vascular dementia (Freitas et al., 2012). In a sample of participants who had previously experienced a stroke, Wong et al. (2015) found a strong correlation $(r=0.87)$ between the telephone administered MoCA 5-minute protocol and the MoCA, good internal consistency (Cronbach's $\alpha=0.790$, and good test-retest reliability $(\mathrm{ICC}=0.89)$, demonstrating evidence of concurrent validity and reliability.

Lipkus Expanded Health Numeracy Scale. The Lipkus Expanded Health Numeracy Scale (Lipkus, Samsa, \& Rimer, 2001) will be used to assess participant numeracy. The measure consists of 11-items and was developed by adding additional items to a general numeracy measure by Schwartz et al. (1997). The measure developed by Lipkus et al. (2001) added items specifically to assess participant's ability to understand percentages, fractions, and proportions as it relates to medical risk out possible outcomes. Cronbach's alpha coefficients for the expanded scale items ranged from $0.70-0.75$ in three samples of participants making cancer screening decisions (Lipkus et al., 2001). Weller et al. (2013) found a Cronbach's alpha of 0.76 for the 11item measure in a combined sample of over 1900 community-dwelling adults and college students. The measure is scored by summing the total number of correct answers. 
Clinical Vignette. A clinical vignette will be provided to each participant in the study. The vignette will provide hypothetical medical information that the participant will use to make treatment decisions for medical interventions. The vignette will request that the participant imagine himself or herself at the age of 75 with a diagnosis of metastatic lung cancer and Chronic Obstructive Pulmonary Disease (COPD). The vignette states that the individual is no longer responding to treatments and has a prognosis of less than one year to live. Lung cancer was chosen for inclusion in the clinical vignette due to the common occurrence and the progressive nature of the disease. All participants in the study will be provided with the same clinical vignette to reduce potential variance in the data.

Decisional Conflict Scale. The Decisional Conflict Scale (DCS; O’Connor, 1994) measures level of patient uncertainty when making health-related decisions The DCS is a 16item measure containing five subscales: informed, clear values, support, uncertainty, and effective decision. The measure uses a Likert scale consisting of five response categories (1=Strongly Disagree, 2= Disagree, 3=Neither Agree or Disagree, 4=Agree, 5=Strongly Agree). The DCS discriminated significantly $(\mathrm{p}<.001)$ between those who had strong intentions either to accept or to decline invitations to receive influenza vaccine or breast cancer screening and those whose intentions were uncertain. The scale also discriminated significantly $(\mathrm{p}<.001)$ between those who accepted or rejected immunization and those who delayed their decisions to be immunized. There was a significant but weak inverse correlation $(r=-0.16, p<0.05)$ between the DCS and knowledge test scores (O’Connor, 1995). The DCS was also found to have good internal consistency (Cronbach's $\alpha=0.95$ ) in a study of 50 community-dwelling older adults making WV POST medical interventions decisions (Gallegos et al., 2020). To reduce participant 
burden due to the repeated measures design, the current study included two of the subscales (informed and uncertainty) of the DCS.

Satisfaction with Decision Scale. The Satisfaction with Decision Scale (SWD) (HolmesRovner et al., 1996) is a 6-item measure of patient satisfaction with a health care decision. The measure uses a 5-point, Likert response scale ( $1=$ Strongly Disagree, $2=$ Disagree, $3=$ Neither Agree or Disagree, 4=Agree, 5=Strongly Agree). Patient ratings are summed, with higher scores indicating increased satisfaction with decision. Cronbach's alpha was 0.88 using a sample of 252 women making decisions for menopause treatment. The SWD has also demonstrated good internal consistency (Cronbach's alpha $=0.85)$ in a sample of depressed primary care patients (Wills \& Holmes-Rovner, 2003). In a study of 50 community-dwelling older adults making WV POST medical interventions decisions (Gallegos et al., 2020), internal consistency was very good, with Cronbach's $\alpha=0.90$. At a 12-month follow up, satisfaction with the decision scores were significantly correlated with decisional certainty $(r=0.27, \mathrm{p}<.05)$. Construct validity for the SWD was assessed using bivariate correlations between the SWD and similar measures (DCS, overall health, and satisfaction with clinic and health care provider). SWD scores were correlated with subscales of the DCS including: uncertainty $(r=-0.29, p<.01)$ and effective decision subscale $(\mathrm{r}=-0.72, \mathrm{p}<.001)$ (Wills \& Holmes-Rovner, 2003). The SWD also had significant correlations with a measure of satisfaction with primary health care provider in the original study $(\mathrm{r}=0.31, \mathrm{p}<.01)$ and a study using depressed patients $(\mathrm{r}=0.23, \mathrm{p}<.05)$ (HolmesRovner et al., 1996; Wills \& Holmes-Rovner, 2003). Correlations between the SWD and additional measures followed test developers hypothesized pattern of relationships and correlations from two separate validation studies found similar associations between the SWD and additional measures (Holmes-Rovner et al., 1996; Wills \& Holmes-Rovner, 2003). An 
additional item will be added following the 6-item SWD to assess satisfaction with the decisionmaking process. This item will not be combined with the SWD or included during final analyses.

Knowledge Questionnaire. A 20-item questionnaire was adapted from a previous study (Gallegos et al., 2020) to evaluate participant knowledge of treatment options and associated risks and benefits for each of the four medical decisions. The questionnaire consisted of multiple-choice items based on information relevant to treatment options specific to the WV POST. Composite knowledge scores were created for each medical decision (CPR, medical interventions, fluids, nutrition) based on item content, by summing the number of correct answers.

Aid Evaluation Questionnaire. A 9-item questionnaire was developed to assess participants' experiences with the video decision aid. Items were included to assess for patient comfort, perceived usefulness, bias, and general acceptability of the aid. Items were modeled from similar evaluation questionnaires used in other video-based decision aid studies (e.g. ElJawahri et al., 2010; Volandes et al., 2012) as well as from evaluation criteria for decision aids set forth by the International Patient Decision Aid Standards (Elwyn et al., 2006). Items were rated using a 5-point, Likert scale (1=Strongly Disagree, $2=$ Disagree, $3=$ Neither Agree or Disagree, 4=Agree, 5=Strongly Agree).

\section{Procedure}

Participants were guided through the study procedures by the graduate student investigator and undergraduate research assistants at WVU. All researchers received required trainings for human subjects' research prior to interacting with participants including: conflict of interest, responsible conduct of research, and HIPAA. The undergraduate research assistants were supervised by the graduate research assistant to ensure the study protocol was followed. 
Participants completed the study measures and questionnaires using a laptop computer. All responses were collected using REDCap, an online platform for collecting survey responses.

After providing informed consent participants were assigned to conditions using sealed envelopes. Block randomization was also utilized in efforts to assign participants evenly based on years of education. Participants with greater than twelve years of education were given sealed envelopes with an "A" while participants with twelve years or less of education were given envelopes with a "B." Each envelope contained a number to designate the assigned condition. The number sequence was created using a random number generator in attempt to randomize approximately even numbers of participants to each condition.

First, participants completed a demographics questionnaire. Next, the participants completed a measure of numeracy. Participants were then given a copy of the WV POST informational leaflet, which summarizes the medical decisions contained in the POST. Then participants were provided with a hypothetical vignette for the purpose of completing the study. The vignette stated that the participant has end-stage cancer and is no longer responding to chemotherapy or other treatments.

Participants then made pre-test treatment decisions for the four medical decisions in the WV POST (CPR, medical interventions, IV fluids, and nutrition) and gave ratings of knowledge, decisional conflict, and satisfaction for each decision.

Then participants viewed a video on a computer. Participants assigned to the control condition viewed a 13-minute educational video about the benefits of exercise. Participants assigned to the intervention condition viewed the 11-minute decision aid developed for the WV POST. 
After viewing the video, participants assigned to both conditions provided post-test preferences for medical decisions in the WV POST and gave ratings of knowledge, decisional conflict, and satisfaction for each decision. Lastly, participants completed a 9-item questionnaire to assess the utility and acceptability of the aid. See Figure 1 for Procedures flowchart. 


\section{Figure 1.}

Flowchart of Procedures

Participants recruited via study advertisements

Participants completed Aid Evaluation (intervention group only)
Participants randomized to conditions

\section{Participants completed post- intervention ratings:$$
\text { Care }
$$ \\ Preferences \\ Knowledge \\ Decisional Conflict}

Satisfaction
Administetred baseline questionnaires:

Demographics Numeracy

Participants viewed video (aid or control)
Provided

Clinical

vignette and

POST leaflet

Participants completed pre-

intervention ratings:

Care

Preferences

Knowledge

Decisional

Conflict

Satisfaction 


\section{Results}

\section{Checking Assumptions}

Prior to beginning statistical analyses, data were examined for adherence to statistical assumptions. Normality was assessed by examining standardized skew and kurtosis statistics. Two variables (post-intervention medical interventions knowledge and post-intervention medically administered fluid knowledge) had a standardized skew value greater than 3.2 (-3.7, 3.3, respectively). The square root and $\log$ transformed variables (post-intervention medical interventions knowledge and post-intervention medically administered fluid knowledge) were entered into the MANCOVA models and had no significant effect on results. Thus, final analyses included the original untransformed variables. Levene's test of homogeneity of variance and Box's M test homogeneity of covariance were not significant at the .001 level, indicating no violations of homogeneity of variance or covariance assumptions. There were no multivariate outliers based on the Mahalanobis distance test.

Examination of bivariate correlations amongst decisional conflict and satisfaction variables indicated the presence of multicollinearity (See Tables $1 \& 2$ for correlations among covariates and dependent variables), which violates an assumption of MANCOVA analyses. Recommendations for reducing multicollinearity (Field, 2013; Tabachnick \& Fidell, 2014) include either removing one of the strongly-correlated variables or combining the two variables into one composite variable. Although forming a composite variable would assist in addressing the multicollinearity issue, it also would produce less meaningful results. The composite variable would represent a previously unknown construct based on the conflict and satisfaction variables. Therefore, interpreting findings or drawing conclusions about the significance would be particularly challenging. There is no standard technique or guideline for choosing which variable 
to omit from analyses. The satisfaction variable was removed from the MANCOVA analyses and separate one-way ANCOVAs were conducted for each medical decision to examine the effect of the video aid on satisfaction.

\section{Preliminary Analyses}

Participant demographic characteristics of the study conditions were compared using independent samples t-tests. There were no significant differences between groups for any measured demographic variables. See Table 3 for additional information. Based on additional independent samples t-tests, there were no statistically significant differences at pre-intervention for ratings of knowledge or decisional conflict between the control and intervention groups for any of the four medical decisions.

To identify potential covariates, linear regression analyses were conducted to assess for significant relations between demographic characteristics and dependent variables. Age, education, marital status, previous involvement in end-of-life decision-making, employment status, and presence of medical orders or advance directives were all found to be significant with at least one dependent variable, however there were no identifiable patterns or presence of variables that consistently were related to a dependent variable or particular medical decision. Individual models were conducted as proposed and including potential covariates. There were no significant changes to the models as a result, thus final analyses included only the originally proposed covariates.

Items contained in the knowledge questionnaire were examined prior to final analyses to assess difficulty. Item difficulty was examined at post-intervention for the intervention group. No single item had a difficulty below 0.5 , which is above the recommended threshold for difficult 
items (0.2 - 0.3; (Abdulghani et al., 2014; Mitra et al., 2009), therefore all items were included in final analyses.

\section{Descriptive Statistics}

Sixty-four adults, aged 50 and over, participated in the study. One individual (Age $=80)$ was excluded from participating in the study due to suspected cognitive impairment as evidenced by a score of 7 on the Montreal Cognitive Assessment (MoCA) 5-minute protocol. The participants were randomly assigned to Control $(\mathrm{N}=28)$ and Intervention $(\mathrm{N}=36)$ groups. The mean age for all participants was $64.53(\mathrm{SD}=8.25)$. Participant age did not significantly differ between the control $(\mathrm{M}=64.36, \mathrm{SD}=8.21)$ and intervention groups $(\mathrm{M}=64.67, \mathrm{SD}=8.40)$. Each condition had an equal number of participants ( 2 per condition) with 12 years of education or less. Mean number of education years for all study participants was $16.8(\mathrm{SD}=3.13)$. Education years did not significantly differ between control $(\mathrm{M}=16.18, \mathrm{SD}=2.90)$ and intervention groups $(\mathrm{M}=17.31, \mathrm{SD}=3.25)$. See Table 4 for additional demographic characteristics of the participants. See Table 5 for descriptive statistics for covariates and outcome variables.

\section{Aim 1}

The first aim sought to explore the effect of a decision aid on knowledge, decisional conflict, and satisfaction for each of the medical decisions contained in the WV POST. Four oneway multivariate analyses of covariance (MANCOVA) analyses were conducted to examine the effect of the intervention (video aid, control) on two decisional outcomes (knowledge and decisional conflict) across four different medical decisions (CPR, medical interventions, IV fluids, feeding tubes). Participant numeracy and pre-intervention ratings of knowledge and decisional conflict were entered into the MANCOVA models as covariates to control for preintervention levels of these variables. Additionally, four ANCOVAs were conducted to examine 
the effect of the intervention on satisfaction for each of the four medical decisions, controlling for participant numeracy and pre-intervention ratings of satisfaction.

\section{CPR}

A significant Wilk's $\Lambda$ value $\mathrm{F}(2,58)=24.258, \mathrm{p}<.001, \eta \mathrm{p} 2=.455$, indicated a significant main effect of the intervention. Follow-up univariate $F$ tests revealed that participants between groups significantly differed on post-intervention CPR knowledge, $F(1,59)=42.844$, $p$ $<.001, \eta \mathrm{p} 2=.421$, and decisional conflict $\mathrm{F}(1,59)=17.892, \mathrm{p}<.001, \eta \mathrm{p} 2=.233$. Participants who viewed the aid were more knowledgeable and less conflicted at post-intervention than participants who did not view the aid. Results from a one-way ANCOVA identified a significant effect of the intervention on post-intervention CPR satisfaction after controlling for numeracy and pre-intervention ratings, $\mathrm{F}(1,60)=7.96, \mathrm{p}<.05, \eta \mathrm{p} 2=.117$. Participants who viewed the aid were more satisfied with their decision at post-intervention than participants who did not view the aid. See Tables 5, 6, \& 7 for additional details of analyses.

\section{Medical Interventions}

A significant Wilk's $\Lambda$ value $\mathrm{F}(2,58)=25.204, \mathrm{p}<.001, \eta p 2=.465$, indicated a significant main effect of the intervention. Follow-up univariate $F$ tests revealed that participants between groups significantly differed on post-intervention medical interventions knowledge, $\mathrm{F}(1,59)=20.475, \mathrm{p}<.001, \eta \mathrm{p} 2=.258$, and decisional conflict $\mathrm{F}(1,59)=31.017, \mathrm{p}<.001, \eta \mathrm{p} 2=$ .345. Participants who viewed the aid were more knowledgeable and less conflicted at postintervention than participants who did not view the aid. Results from a one-way ANCOVA identified a significant effect of the intervention on post-intervention medical interventions satisfaction after controlling for numeracy and pre-intervention ratings, $\mathrm{F}(1,60)=14.72, \mathrm{p}<$ $.001, \eta p 2=.20$. Participants who viewed the aid were more satisfied with their decision at post- 
intervention than participants who did not view the aid. See Tables $8,9 \& 10$ for additional details of analyses.

\section{Fluids}

A significant Wilk's $\Lambda$ value $\mathrm{F}(2,58)=27.014, \mathrm{p}<.001, \eta \mathrm{p} 2=.482$, indicated a significant main effect of the intervention. Follow-up univariate $F$ tests revealed that participants between groups significantly differed on post-intervention IV fluids knowledge, $\mathrm{F}(1,59)=$ 31.004, $\mathrm{p}<.001, \eta \mathrm{p} 2=.344$, and decisional conflict $\mathrm{F}(1,59)=11.718, \mathrm{p}=.001, \eta \mathrm{p} 2=.166$ Participants who viewed the aid were more knowledgeable and less conflicted at postintervention than participants who did not view the aid. Results from a one-way ANCOVA identified a significant effect of the intervention on post-intervention IV fluids satisfaction after controlling for numeracy and pre-intervention ratings, $\mathrm{F}(1,60)=6.38, \mathrm{p}<.05, \eta \mathrm{p} 2=.10$.

Participants who viewed the aid were more satisfied with their decision at post-intervention than participants who did not view the aid. See Tables $11,12, \& 13$ for additional details of analyses.

\section{Feeding Tubes}

A significant Wilk's $\Lambda$ value $\mathrm{F}(2,58)=8.115, \mathrm{p}=.001, \eta \mathrm{p} 2=.219$, indicated a significant main effect of the intervention. Follow-up univariate $F$ tests revealed that participants between groups significantly differed on post-intervention decisional conflict, $F(1,59)=16.411, \mathrm{p}<.001$, $\eta p 2=.218$, but not nutrition knowledge $\mathrm{F}(1,59)=1.905, \mathrm{p}=.173, \eta \mathrm{p} 2=.031$. Participants who viewed the aid were less conflicted at post-intervention than participants who did not view the aid. There were no significant differences of knowledge between groups. Results from a one-way ANCOVA identified a significant effect of the intervention on post-intervention feeding tube satisfaction after controlling for numeracy and pre-intervention ratings, $F(1,60)=12.81, p=$ $.001, \eta p 2=.18$. Participants who viewed the aid were more satisfied with their decision at post- 
intervention than participants who did not view the aid. See Tables $14,15, \& 16$ for additional details of analyses.

\begin{abstract}
$\operatorname{Aim} 2$
The second aim was to explore the association between viewing the aid and participants' decisions for medical treatments. Four Chi-square tests of independence were conducted to explore the relation between assigned group (treatment, control) and four different medical decisions (CPR, medical interventions, IV fluids, feeding tubes) made by participants during the study contained in the West Virginia POST form. Follow-up logistic regression analyses were conducted to determine whether the intervention influenced decisions made at post-intervention after controlling for pre-intervention decision.
\end{abstract}

\title{
Research Question 13
}

A Chi-square test of independence was performed to examine the relation between group and participant decision for CPR (attempt CPR, Do-not-attempt) at post-intervention. There was no significant association between group and medical decision made, $X^{2}(1, N=64)=.301, p=$ .583. Participants in the intervention group were not more likely to choose DNR than participants in the control group.

A binary logistic regression was conducted to examine whether post-intervention CPR decision was influenced by the video aid, while controlling for pre-intervention CPR decision. The overall regression model was significant, $\chi^{2}(2, N=64)=14.83$, Nagelkerke $\mathrm{R}^{2}=.27, \mathrm{p}$ $=.001$. Pre-intervention CPR decision significantly predicted CPR decision at post-intervention, $\mathrm{B}=2.188$, Wald $\chi^{2}=11.97, \mathrm{p}=.001$, however treatment group was not found to significantly predict post-intervention CPR decision, $\mathrm{B}=0.413$, Wald $\chi^{2}=0.50, \mathrm{p}=.480$. Viewing the decision aid was not found to predict participant medical decisions for CPR at post-intervention. 


\section{Research Question 14}

A second Chi-square test of independence was performed to examine the relation between treatment group and participant decision for medical interventions (comfort measures, limited additional interventions, full interventions). There was no significant association between group and medical decision made, $\mathrm{X}^{2}(2, \mathrm{~N}=64)=3.317, \mathrm{p}=.190$. Participants in the intervention group were not more likely to choose limited additional interventions or comfort measures than participants in the control group.

A multinomial logistic regression was conducted to examine whether post-intervention medical interventions decision was predicted by assigned treatment group, while controlling for pre-intervention medical interventions decision. The overall regression model was significant, $\chi^{2}(6, N=64)=36.40$, Nagelkerke $\mathrm{R}^{2}=.51, \mathrm{p}<.001$. However, treatment group was not found to significantly predict participants' post-intervention medical decisions, $\mathrm{B}=-1.90$, Wald $\chi^{2}=3.06$, $\mathrm{p}=.080$. Viewing the decision aid was not found to predict participant medical decisions for medical interventions at post-intervention.

\section{Research Question 15}

A third Chi-square test of independence was performed to examine the relation between group and participant decision for IV fluids (no IV fluids, IV fluid trial period). There was no significant association between group and medical decision made, $\mathrm{X}^{2}(1, \mathrm{~N}=64)=.795, \mathrm{p}=.373$. Participants in the intervention group were not more likely to choose to forgo IV fluids than participants in the control group.

A binary logistic regression was conducted to examine whether post-intervention IV fluids decision was predicted by assigned treatment group, while controlling for pre-intervention IV fluids decision. The overall regression model was significant, $\chi^{2}(2, N=64)=25.16$, 
Nagelkerke $\mathrm{R}^{2}=.47, \mathrm{p}<.001$. Pre-intervention IV fluids decision significantly predicted IV fluids decision at post-intervention, $\mathrm{B}=3.322$, Wald $\chi^{2}=15.77, \mathrm{p}<.001$, however treatment group was not found to significantly predict participants' post-intervention IV fluids decision, B $=0.501$, Wald $\chi^{2}=0.49, \mathrm{p}=.486$. Viewing the decision aid was not found to predict participant medical decisions for IV fluids at post-intervention.

\section{Research Question 16}

A fourth Chi-square test of independence was performed to examine the relation between treatment group and participant decision for feeding tubes (no feeding tube, feeding tube longterm). There was no significant association between group and medical decision made, $\mathrm{X}^{2}(1, \mathrm{~N}=$ $64)=.284, p=.594$. Participants in the intervention group were not more likely to decline a feeding tube than participants in the control group.

A binary logistic regression was conducted to examine whether post-intervention feeding tube decision was predicted by assigned treatment group, while controlling for pre-intervention feeding tube decision. The overall regression model was significant, $\chi^{2}(2, N=64)=10.49$, Nagelkerke $\mathrm{R}^{2}=.23, \mathrm{p}<.01$. Pre-intervention tube feeding decision significantly predicted tube feeding decision at post-intervention, $\mathrm{B}=2.480$, Wald $\chi^{2}=9.39, \mathrm{p}<.01$, however treatment group was not found to significantly predict participants' post-intervention feeding tubes decision, $\mathrm{B}=-0.385$, Wald $\chi^{2}=0.32, \mathrm{p}=.569$. Viewing the decision aid was not found to predict participant medical decisions for feeding tubes at post-intervention.

\section{Aid Evaluation}

Participant feedback regarding the usefulness and utility of the aid was overwhelmingly positive. Using ratings of strongly agree or agree, a large majority of participants (88.9\%) rated the aid as helpful, that they would recommend the video to a friend or family member $(94.4 \%)$ 
and felt comfortable viewing the aid (97\%). Participants felt that the video made clear the decisions to be made $(91.7 \%)$, provided alternative options for each decision $(91.7 \%)$, discussed associated risks/benefits of each option (88.9\%), and provided clear probabilities of potential outcomes of treatment options (94.4\%). A small minority of participants $(11.1 \%)$ reported belief that the aid was biased towards a specific option. See Tables 21 for complete results of participant responses.

\section{Discussion}

The current study evaluated the effect of a video decision aid for the West Virginia POST. The study had two primary aims. The first aim was to evaluate the effect of the decision aid on decision-making outcome variables including knowledge, decisional conflict, and satisfaction for each of the four medical decisions contained in the WV POST.

The first set of analyses for the first aim examined whether the video aid had an effect on participant knowledge, decisional conflict, and satisfaction for the CPR decision. The results obtained supported the study hypotheses that the video aid would be effective in increasing participant knowledge of CPR, decreasing decisional conflict, and increasing satisfaction with decision at post-intervention measurement.

The present findings are consistent with the current literature that has shown increased knowledge (El-Jawahri et al., 2015; Epstein et al., 2013; Volandes et al., 2013) after using a CPR-focused decision aid. For example, studies have found increases in knowledge with patients with advanced cancers (Epstein et al., 2013; Volandes et al., 2013), advanced heart failure (ElJawahri et al., 2016), and medically frail patients with a prognosis of less than one year to live (El-Jawahri et al., 2015). Increasing knowledge about the risks and benefits is especially important given the common misconceptions about the effectiveness of CPR and the existing 
research that demonstrates participants overestimate chances of survival following CPR (Adams \& Snedden, 2006; Sundar, Do, O’Cathail, 2014). The aid provides necessary information about the effectiveness and long-term survival outcomes of frail and elderly individuals, which will allow viewers to make better informed decisions about their preferences for receiving CPR.

The present finds also are consistent with previous research showing decreased decisional conflict with the use of an aid. El-Jawahri et al. (2010) found a video aid to be effective in reducing decisional conflict in a sample of patients with advanced cancer, utilizing the 3-item Uncertainty subscale of the Decisional Conflict Scale. The present study yielded similar findings but also included the 3-item Informed subscale which directly assesses perceptions of being informed of the treatment options, benefits, and risks of each option. The inclusion of the additional subscale strengthens the findings of the current study given one of the primary goals of a decision aid is to equip participants with sufficient information for the purpose of making well-informed decisions. Also, given the potential risks of CPR such as brain damage and death, it is vital for participants to feel more informed.

The second set of analyses examined whether the video aid had an effect on participant knowledge, decisional conflict, and satisfaction for the medical interventions decision. The results obtained supported the study hypotheses that the video aid would be effective in increasing participant knowledge of medical interventions, decreasing decisional conflict, and increasing satisfaction at post-intervention measurement.

These findings are consistent with the current literature that has shown increased knowledge (Hanson et al., 2017; Volandes et al., 2011) after using a decision aid for medical interventions. Effects of an aid improving knowledge have been demonstrated for surrogate 
decision makers of nursing home residents with advanced dementia (Hanson et al., 2017) and elderly primary care patients (Volandes et al., 2011).

Knowledge and understanding of the different levels of medical interventions, and included medical treatments, is vital for individuals completing POST forms. This is due to the interconnectedness of preferences for CPR and medical interventions. Individuals who prefer to receive CPR are, by definition in the POST form, also selecting preference for full interventions. Full interventions include CPR and all other medical interventions to sustain life. However, individuals who do not wish to receive CPR in the event of cardiac arrest, have a choice to select either limited additional interventions (i.e. basic medical treatments) or comfort measures (i.e. symptom management). Improving knowledge of medical interventions is critical due to the range and scope of treatments associated with each level of medical interventions. It is necessary to ensure that participants are aware of the differences between levels in order to promote wellinformed decision-making.

Findings obtained in the current study demonstrating decreased decisional conflict after using an aid for medical interventions are also consistent with previous research. Jawahri et al. (2010) also evaluated the effect of an aid on reducing decisional conflict with a medical interventions decision. This study utilized only the 3-item Uncertainty subscale, while the present study extended these findings and also included items related to participant perception of feeling informed about the choices and associated risks and benefits. As stated above, the inclusion of the informed subscale is important due to primary goals of decision aids as well needs of being adequately informed of potential risks and benefits of the decision.

The third set of analyses examined whether the video aid had an effect on participant knowledge, decisional conflict, and satisfaction for the feeding tubes decision. The results 
obtained supported the study hypothesis that the video aid would be effective in decreasing decisional conflict and increasing satisfaction at post-intervention measurement. However, results did not support the hypothesis that the aid would improve participant knowledge of feeding tubes.

Despite several previous studies finding decision aids to be effective in improving knowledge of feeding tubes after using a decision aid (Chang et al., 2015; Kuraoka \& Nakayama, 2014; Mitchell, Tetroe, \& O’Connor, 2001), there was no effect found in the current study. One possible reason is the high percentage of correct answers at both pre- and post-intervention for both groups. Items related to medically administered nutrition likely were not sufficiently difficult, resulting in a ceiling effect that precluded a demonstration of improvement with aid. Participants mean pre-intervention feeding tube knowledge was 2.69 compared to postintervention mean score of 3.31. Another potential reason for the lack of significant differences could be the limited information contained in the current decision aid compared with the aids evaluated in other studies. The current aid provided information limited to tube feeding and associated risks. Other studies (Hanson et al., 2011; Kuraoka \& Nakayama, 2014; Mitchell, Tetroe, \& O'Connor, 2001) presented information on feeding options in the context of advanced dementia and targeted surrogate decision-makers. Additional content and detail were included in other decision aids about dementia, guidelines for surrogate decision-making, and explanation of different types of feeding tubes. This additional information resulted in a decision aid with significantly more content, and thus a knowledge questionnaire with significantly more items. The increased number of items can allow for potentially greater variance between and within groups as well as more opportunity to show increased knowledge change from pre- to postintervention measurement. 
Findings obtained in the current study demonstrating decreased decisional conflict after using an aid for nutrition decisions are consistent with previous research. Multiple studies (Hanson et al., 2011; Kuraoka \& Nakayama, 2014; Mitchell, Tetroe, \& O’Connor, 2001) have demonstrated decreased decisional conflict about feeding tube decisions as a result of using a decision aid in samples of surrogate decision-makers. Decreasing decisional conflict related to feeding tube decisions is especially important given the potential context for when this decision may occur. Tube feeding decisions are sometimes made in response to diminishing cognitive and functional abilities associated with dementia, such as difficulty or inability to swallow foods. Ensuring that patients feel informed at the time of decision-making, while still cognitively intact, regarding the potential need for feeding tubes, as well as feeling clear about the risks and benefits, is vital.

The fourth set of analyses examined whether the video aid had an effect on participant knowledge, decisional conflict, and satisfaction for the IV fluids decision. The results obtained supported the study hypotheses that the video aid would be effective in increasing knowledge of IV fluids, decreasing decisional conflict, and increasing satisfaction at post-intervention measurement.

There are no apparent published studies evaluating the effectiveness of a decision aid for IV fluids decisions. Therefore, the improvements in knowledge and reduction of decisional conflict provide the first evidence to support the use of a decision aid in individuals making decisions related to IV fluids. Development and evaluation of a decision aid for IV fluids is extremely important given the potential use of IV fluids near the end-of-life. Misconceptions about the purpose of IV fluids and myths such as a patient "dying of thirst" highlight the importance of accurately conveying information about the nature and scope of IV fluids. An aid, 
such as the one described in the current study, can increase the likelihood that patients or other decision-makers are well-informed about the treatment and associated risks/benefits prior to making a decision.

Although findings from the current study demonstrated increased participant satisfaction when making a CPR, medical interventions, feeding tube, and IV fluids decisions following the use of the video aid, there is a paucity of research that has examined satisfaction with these specific medical decisions. Hanson et al. (2011) is the only study that measured satisfaction with a decision aid for a POLST-related medical decision. The researchers found that surrogate decision-makers, making a feeding tube decision for a family member with advanced dementia living in a nursing home, had increased satisfaction three months after use of the aid. However, there was no significant difference in satisfaction between surrogates who received a print/audio aid vs surrogates who received usual care. There is a significant body of research showing improvement of satisfaction following use of a decision aid (Stacey et al., 2017) including decision aids for breast cancer treatment (Heller et al., 2008), blood transfusions (Laupacis et al., 2006), and birthing method (Montgomery et al., 2007). Findings from the present study are important in part because it is the first study to show satisfaction improvement for end-of-life related decisions as a result of using a decision aid. Improved satisfaction with end-of-life decisions is also an important in light of the positive relation between satisfaction and shared decision-making (Hinkle et al., 2015) and increased discussions of patient wishes and values (Gries et al., 2008). The use of a decision aid provides participants with information necessary to participate meaningfully in medical discussions and facilitates opportunities to discuss patient wishes with medical teams. 
Findings from Aim 1 analyses have important implications for the future literature evaluating decision aids for end-of-life medical treatments. Previous researchers have evaluated aids that contain information about multiple types of end-of-life medical decisions, but no aid including content to assist participants in completing all the decisions contained in a POLST form has been evaluated. There are existing decision aids that have been developed for most of the medical decisions (CPR, medical interventions, and medically administered nutrition) contained in the POLST. In theory, these existing aids could be combined or shown consecutively to assist in completing POST forms. However, this amalgamation of various aids, would yield an inefficient and lengthy aid that would require considerable time, sustained focus, and attention.

The second aim was to explore the association between viewing the aid on participants' decisions for medical treatments. Analyses examined the association between viewing a decision aid and the treatment decisions made for each of the four WV POST medical decisions. There was no relation found between viewing the decision aid and treatment decision made.

The results obtained did not support the hypotheses that participants who viewed the aid would be more likely to choose comfort measures or forgo CPR compared to participants who did not view the aid. These results were surprising for a number of reasons. First, previous research (El-Jawahri et al., 2016; Epstein et al., 2013; Volandes et al., 2011) has largely demonstrated that individuals are more likely to prefer comfort measures over full interventions and choose to forgo CPR after viewing a video aid for end-of-life medical decisions. A possible explanation for the lack of effect of the video aid on treatment decision is the characteristics of participants included in the present study. In several other RCT studies examining the effect of a video aid on preference for medical treatment, participants were recruited from inpatient critical 
care settings (El-Jawahri et al., 2015), had advanced cancer (Volandes et al., 2013), or had heart failure (El-Jawahri et al., 2016). Additionally, the mean age of participants in previous research with elderly patients (Volandes et al., 2009; Volandes et al., 2011) were in the mid-seventies. Participants in the current study were overwhelmingly healthy community-dwelling adults and were relatively younger (Mean age $=64$ ) than participants in studies that targeted older adults. The presence of either life-limiting illness or advanced age are both factors that could influence participant medical decisions. Younger participants, or those who are in good health, may not be able to imagine themselves in a significantly different state than their own. Conversely, individuals who are older, hospitalized in critical care units, or have a prognosis of less than one year to live, may have additional life experience with these medical decisions, and/or previous discussions with health care providers about the utility of life-prolonging medical treatments within the context of their own medical situation.

Participants generally described the video as informative and helpful in making a decision. The high degree of comfort reported by participants when viewing the aid is especially vital given the potentially distressing medical information presented and in-depth discussion about end-of-life medical care. A small portion of respondents (11\%) endorsed potential bias of the aid toward a particular medical option. The item assessing bias was the only negatively worded item on the questionnaire. This could potentially have created error if some participants did not realize the change.

Participant feedback regarding the usefulness and utility of the aid was overwhelmingly positive. Using ratings of strongly agree or agree, a large majority of participants (88.9\%) rated the aid as helpful, that they would recommend the video to a friend or family member $(94.4 \%)$ and felt comfortable viewing the aid (97\%). Participants felt that the video made clear the 
decisions to be made (91.7\%), provided alternative options for each decision $(91.7 \%)$, discussed associated risks/benefits of each option (88.9\%), and provided clear probabilities of potential outcomes of treatment options (94.4\%). A small minority of participants (11.1\%) reported belief that the aid was biased towards a specific option. See Tables 13 for complete results of participant responses.

\section{Limitations}

There are several important limitations to discuss regarding the current study. The sample was very highly educated, overwhelmingly Caucasian, and generally healthy. Although these characteristics were not found to significantly influence study results, participants were not as representative of the general population as desired, thus limiting the generalizability of the findings. The use of hypothetical vignettes is also a potential limitation of the study. Although it is a common practice in published studies evaluating decisions aids to use hypothetical clinical vignettes, this method may introduce potential measurement error and limit generalizability to patients making these decisions in real-world medical scenarios medical populations (Ulrich \& Ratcliffe, 2007). Participants may satisfice (Simon, 1956), or process information contained in the vignette or study less carefully compared with real-world conditions (Stolte, 1994). This could lead to participants not appropriately weighing the associated risks and benefits of each option, or not taking into consideration their personal values when making a decision. It is also possible that participants forgot to utilize the vignette over the course of completing study measures. This potential change in perspective could significantly alter the types of decisions made by participants and influence how conflicted or satisfied they were while making decisions. Nevertheless, the use of vignettes enhanced the internal validity of the study by establishing a uniform set of circumstances for participants to make decisions and respond to measures. Last, 
additional analyses (included in the appendix) were conducted to examine potential reasons for multicollinearity. Results from these analyses suggested potential suppression effects based on the inclusion of pre-intervention ratings as covariates. Although it is not clear the cause of the potential suppression effects, it is possible that ceiling effects, or high stability of responses from pre- to post-intervention ratings of decisional outcomes could have contributed to this effect.

\section{Future Directions}

There are several directions for future research. A much-needed area for further research would be the implementation and evaluation of the current aid with individuals with life-limiting illnesses. First, evaluation with patients could provide valuable insight about the acceptability of the aid as a whole, as well as presentation of content included in the aid. Interviews with patients could potentially uncover additional information that would be helpful during the decisionmaking process. Evaluation with clinical samples is also needed to examine the effects of the aid on real-world medical decision-making, which could address limitations of the generalizability

of the results of the current study. In addition to evaluating the aid with patients, further research should seek to examine the aid with surrogate decision-makers.

Given that the POLST paradigm forms vary slightly in presentation of options and content across the United States, future research should seek to develop decision aids for each variation. Once aids have been more widely developed for POLST paradigm forms, it would then be possible to explore methods of standardizing the completion of POLST forms in clinical practice, specifically when the aid is used, what medical provider would provide relevant information, and timing for completion. Additional research could also evaluate participant outcomes such as decisional conflict or satisfaction for unique variations of the POLST. 
Additional research could also evaluate the effects of participant cognitive biases and heuristics and their influence on medical decision-making (Blumenthal-Barby, 2015). Further, future research could examine the effect of information framing (Almashat et al., 2008) and balancing information (Abhynakar et al., 2013) in decision aids for POLST decisions. This information could be vital when developing future aids and provide helpful insight about how best to provide patients and surrogates with medical information.

\section{Conclusions and Implications}

The current study had two primary aims. The first was to examine the effects of a video decision aid on decisional outcomes for the medical decisions contained in the WV POST. The second aim was to explore the relation between viewing the aid and medical decision made. The aid was found to be effective in improving knowledge and decreasing decisional conflict in a non-patient sample of community-dwelling older adults making hypothetical medical decisions. These findings are important because it demonstrates the individuals can be taught necessary information to make an informed decision while completing a POLST form, and that when using a decision aid, participants feel more informed and less uncertain about their decision. The aid was perceived by participants to be an unbiased tool that provides helpful information for making a medical decision. Notwithstanding the limitations of this study, the results provide foundational support for the use of decision aids with multi-decision end-of-life care orders, such as POLST forms. 


\section{References}

Abdulghani, H. M., Ahmad, F., Ponnamperuma, G. G., Khalil, M. S., \& Aldrees, A. (2014). The relationship between non-functioning distractors and item difficulty of multiple-choice questions: A descriptive analysis. Journal of Health Specialties, 2(4), 148.

Abhyankar, P., Volk, R. J., Blumenthal-Barby, J., Bravo, P., Buchholz, A., Ozanne, E., Vidal, D. C., Col, N., \& Stalmeier, P. (2013). Balancing the presentation of information and options in patient decision aids: an updated review. BMC Medical Informatics and Decision Making, 13(S2), S6.

Adams, D. H., \& Snedden, D. P. (2006). How misconceptions among elderly patients regarding survival outcomes of inpatient cardiopulmonary resuscitation affect do-not-resuscitate orders. The Journal of the American Osteopathic Association, 106(7), 402-404.

Almashat, S., Ayotte, B., Edelstein, B., \& Margrett, J. (2008). Framing effect debiasing in medical decision making. Patient Education and Counseling, 71(1), 102-107.

Barnato, A. E., Herndon, M. B., Anthony, D. L., Gallagher, P. M., Skinner, J. S., Bynum, J. P., \& Fisher, E. S. (2007). Are regional variations in end-of-life care intensity explained by patient preferences? A Study of the US Medicare Population. Medical Care, 45(5), 386393. doi:10.1097/01.mlr.0000255248.79308.41

Belanger, E. (2017). Shared decision-making in palliative care: Research priorities to align care with patients' values. Palliative Medicine, 31(7), 585-586. http://doi.org/10.1177/0269216317713864

Blumenthal-Barby, J. S., \& Krieger, H. (2015). Cognitive biases and heuristics in medical decision making: A critical review using a systematic search strategy. Medical Decision Making, 35(4), 539-557. 
Bomba, P. A., \& Orem, K. (2015). Lessons learned from New York's community approach to advance care planning and MOLAT. Annals of Palliative Medicine, 4(1), 10-21. http://doi.org/10.3978/j.issn.2224-5820.2015.01.05

Caprio, A. J., Rollins, V. P., \& Roberts, E. (2012). Health care professionals' perceptions and use of the medical orders for scope of treatment (MOST) form in North Carolina nursing homes. Journal of the American Medical Directors Association, 13(2), 162-168. http://doi.org/10.1016/j.jamda.2010.07.006

Cardona-Morrell, M., Benfatti-Olivato, G., Jansen, J., Turner, R. M., Fajardo-Pulido, D., \& Hillman, K. (2017). A systematic review of effectiveness of decision aids to assist older patients at the end of life. Patient education and counseling, 100(3), 425-435. http://dx.doi.org/10.1016/j.pec.2016.10.007

Charles, C., Gafni, A., \& Whelan, T. (1997). Shared decision-making in the medical encounter: What does it mean? (Or it takes, at least two to tango). Social Science and Medicine, 44(5), 681-692. http://doi.org/10.1016/S0277-9536(96)00221-3

Clemency, B., Cordes, C. C., Lindstrom, H. A., Basior, J. M., \& Waldrop, D. P. (2017). Decisions by default: Incomplete and contradictory MOLST in emergency care. Journal of the American Medical Directors Association, 18(1), 35-39.

Collier, J., Kelsberg, G., \& Safranek, S. (2018). Clinical Inquiries: How well do POLST forms assure that patients get the end-of-life care they requested? Journal of Family Practice, $67(4), 249-251$.

Einterz, S. F., Gilliam, R., Chang Lin, F., McBride, J. M., \& Hanson, L. C. (2014). Development and testing of a decision aid on goals of care for advanced dementia. Journal of the American Medical Directors Association, 15(4), 251-255. 


\section{http://doi.org/10.1016/j.jamda.2013.11.020}

El-Jawahri, A., Mitchell, S. L., Paasche-Orlow, M. K., Temel, J. S., Jackson, V. A., Rutledge, R. R., ... Volandes, A. E. (2015). A randomized controlled trial of a CPR and intubation video decision support tool for hospitalized patients. Journal of General Internal Medicine, 30(8), 1071-1080. http://doi.org/10.1007/s11606-015-3200-2

El-Jawahri, A., Paasche-Orlow, M. K., Matlock, D., Stevenson, L. W., Lewis, E. F., Stewart, G., ... Volandes, A. E. (2016). Randomized, controlled trial of an advance care planning video decision support tool for patients with advanced heart failure. Circulation, 134(1), 52-60. http://doi.org/10.1161/CIRCULATIONAHA.116.021937

El-Jawahri, A., Podgurski, L. M., Eichler, A. F., Plotkin, S. R., Temel, J. S., Mitchell, S. L., ... Volandes, A. E. (2010). Use of video to facilitate end-of-life discussions with patients with cancer: A randomized controlled trial. Journal of Clinical Oncology, 28(2), 305-310.

\section{http://doi.org/10.1200/JCO.2009.24.7502}

Elwyn, G., O’Connor, A., Stacey, D., Volk, R., Edwards, A., Coulter, A., ... Collaboration, I. P. D. A. S. (IPDAS). (2006). Developing a quality criteria framework for patient decision aids: online international Delphi consensus process. British Medical Journal, 333(7565), 417. http://doi.org/10.1136/bmj.38926.629329.AE

Epstein, A. S., Volandes, A. E., Chen, L. Y., Gary, K. a, Li, Y., Agre, P., ... O’Reilly, E. M. (2013). A randomized controlled trial of a cardiopulmonary resuscitation video in advance care planning for progressive pancreas and hepatobiliary cancer patients. Journal of Palliative Medicine, 16(6), 623-31. http://doi.org/10.1089/jpm.2012.0524

Field, A. (Ed.). (2013). Discovering statistics using IBM SPSS statistics. Sage Publications.

Freitas, S., Simoes, M. R., Alves, L., Vicente, M., \& Santana, I. (2012). Montreal Cognitive 
Assessment (MoCA): Validation study for vascular dementia. Journal of the International Neuropsychological Society, 18(6), 1031-1040.

Gallegos, J, V., Edelstein, B., \& Moss, A, H. (2020). Evaluation of a video decision aid to reduce decisional conflict in physician orders for life-sustaining treatment (POLST) decisionmaking. Journal of Palliative Care. Accepted ahead of publication.

Gries, C. J., Curtis, J. R., Wall, R. J., \& Engelberg, R. A. (2008). Family member satisfaction with end-of-life decision making in the ICU. Chest, 133(3), 704-712.

Gillick, M. R., \& Volandes, A. E., (2009). The psychology if using and creating video decision aids for advance care planning. In D. Murphy \& D. Longo (Eds.), Encyclopedia of Psychology of Decision Making (pp.183-196). New York, NY: Nova Science Publishers.

Freitas, S., Simoes, M. R., Alves, L., Vicente, M., \& Santana, I. (2012). Montreal Cognitive Assessment (MoCA): Validation study for vascular dementia. Journal of the International Neuropsychological Society, 18(6), 1031-1040.

Hachinski, V., Iadecola, C., Petersen, R.C., Breteler, M.M., Nyenhuis, D.L., Black, S.E., \& Leblanc, G.G. (2006). National Institute of Neurological Disorders and Stroke - Canadian Stroke Network Vascular Cognitive Impairment Harmonization Standards. Stroke, 37, $2220-2241$.

Hammes, B. J., Rooney, B. L., Gundrum, J. D., Hickman, S. E., \& Hager, N. (2012). The POLST program: a retrospective review of the demographics of use and outcomes in one community where advance directives are prevalent. Journal of Palliative Medicine, 15(1), 77-85. http://doi.org/10.1089/jpm.2011.0178

Hanson, L. C., Carey, T. S., Caprio, A. J., Lee, T. J., Ersek, M., Garrett, J., ... Mitchell, S. L. (2011). Improving decision-making for feeding options in advanced dementia: A 
randomized, controlled trial. Journal of the American Geriatrics Society, 59(11). http://doi.org/10.1111/j.1532-5415.2011.03629.x

Hanson, L. C., Zimmerman, S., Song, M.-K., Lin, F.-C., Rosemond, C., Carey, T. S., \& Mitchell, S. L. (2017). Effect of the goals of care intervention for advanced dementia. Journal of the American Medical Association Internal Medicine, 177(1), 24. http://doi.org/10.1001/jamainternmed.2016.7031

Hickman, S. E., Hammes, B. J., Torke, A. M., Sudore, R. L., \& Sachs, G. A. (2017). The quality of physician orders for life-sustaining treatment decisions: A pilot study. Journal of Palliative Medicine, 20(2), 155-162. DOI: 10.1089/jpm.2016.0059

Hickman, S. E., Keevern, E., \& Hammes, B. J. (2015). Use of the physician orders for lifesustaining treatment program in the clinical setting: A systematic review of the literature. Journal of the American Geriatrics Society, 63(2), 341-350. http://doi.org/10.1111/jgs.13248

Hickman, S. E., Nelson, C. A., Moss, A. H., Hammes, B. J., Terwilliger, A., Jackson, A., \& Tolle, S. W. (2009). Use of the Physician Orders for Life-Sustaining Treatment (POLST) paradigm program in the hospice setting. Journal of Palliative Medicine, 12(2), 133-41. http://doi.org/10.1089/jpm.2008.0196

Hickman, S. E., Nelson, C. A., Moss, A. H., Tolle, S. W., Perrin, N. A., \& Hammes, B. J. (2011). The consistency between treatments provided to nursing life-sustaining treatment form. Journal of the American Geriatrics Society, 59(11), 2091-2099. http://doi.org/10.1111/j.1532-5415.2011.03656.x

Hickman, S. E., Nelson, C. A., Perrin, N. A., Moss, A. H., Hammes, B. J., \& Tolle, S. W. (2010). A comparison of methods to communicate treatment preferences in nursing facilities: 
Traditional practices versus the physician orders for life-sustaining treatment program.

Journal of the American Geriatrics Society, 58(7), 1241-1248.

http://doi.org/10.1111/j.1532-5415.2010.02955.x

Hickman, S. E., Tolle, S. W., Brummel-Smith, K., \& Carley, M. M. (2004). Use of the physician orders for life-sustaining treatment program in Oregon nursing facilities: Beyond resuscitation status. Journal of the American Geriatrics Society.

Hickman, S. E., Sudore, R. L., Sachs, G. A., Torke, A. M., Myers, A. L., Tang, Q., ... \& Hammes, B. J. (2018). Use of the physician orders for scope of treatment program in Indiana nursing homes. Journal of the American Geriatrics Society. DOI: $10.1111 /$ jgs. 15338

Hinkle, L. J., Bosslet, G. T., \& Torke, A. M. (2015). Factors associated with family satisfaction with end-of-life care in the ICU. Chest, 147(1), 82-93.

Holmes-Rovner, M., Kroll, J., Schmitt, N., Rovner, D. R., Breer, M. L., Rothert, M. L., ... Talarczyk, G. (1996). Patient satisfaction with health care decisions: the satisfaction with decision scale. Medical Decision Making, 16(1), 58-64.

\section{http://doi.org/10.1177/0272989X9601600114}

Jain, A., Corriveau, S., Quinn, K., Gardhouse, A., Vegas, D. B., \& You, J. J. (2015). Video decision aids to assist with advance care planning: a systematic review and metaanalysis. BMJ Open, 5(6), e007491. doi:10.1136/bmjopen-2014-007491

Jennings, L. A., Zingmond, D., Louie, R., Tseng, C. H., Thomas, J., O’Malley, K., \& Wenger, N. S. (2016). Use of the Physician Orders for Life-Sustaining Treatment among California Nursing Home Residents. Journal of General Internal Medicine. http://doi.org/10.1007/s11606-016-3728-9 
Kuraoka, Y., \& Nakayama, K. (2014). A decision aid regarding long-term tube feeding targeting substitute decision makers for cognitively impaired older persons in Japan: A small-scale before-and-after study. BMC Geriatrics, 14(1), 16. http://doi.org/10.1186/1471-2318-14-16

Laupacis, A., O’Connor, A. M., Drake, E. R., Rubens, F. D., Robblee, J. A., Grant, F. C., \& Wells, P. S. (2006). A decision aid for autologous pre-donation in cardiac surgery -- a randomized trial. Patient Education \& Counseling, 61(3), 458-466.

Lee, M. A., Brummel-smith, K., Meyer, J., Drew, N., London, M. R., \& A, M. (2000). Outcomes in a PACE Program. Journal of the American Geriatrics Society, 48, 1219-1225. http://doi.org/10.1111/j.1532-5415.2004.52402.x

Lipkus, I. M., Samsa, G., \& Rimer, B. K. (2001). General performance on a numeracy scale among highly educated samples. Medical Decision Making, 21, 37-44.

MacKinnon, D. P., Krull, J. L., \& Lockwood, C. M. (2000). Equivalence of the mediation, confounding and suppression effect. Prevention Science, 1(4), 173-181.

Makoul, G., \& Clayman, M. L. (2006). An integrative model of shared decision making in medical encounters. Patient Education and Counseling, 60(3), 301-312. http://doi.org/10.1016/j.pec.2005.06.010

McGough, N. N., Hauschildt, B., Mollon, D., \& Fields, W. (2015). Nurses' knowledge and comfort levels using the Physician Orders for Life-sustaining Treatment (POLST) form in the progressive care unit. Geriatric Nursing, 36(1), 21-24.

\section{http://dx.doi.org/10.1016/j.gerinurse.2014.09.001}

Mitchell, S. L., Tetroe, J., \& O’Connor, A. M. (2001). A decision aid for long-term tube feeding in cognitively impaired older persons. Journal of the American Geriatrics Society, 49(3), 313-6. http://doi.org/10.1046/j.1532-5415.2001.4930313.x 
Mitra, N. K., Nagaraja, H. S., Ponnudurai, G., \& Judson, J. P. (2009). The levels of difficulty and discrimination indices in type A multiple choice questions of pre-clinical semester 1 multidisciplinary summative tests. International e-Journal of Science, Medicine \& Education, 3(1), 2-7.

Moss, A. H., Ganjoo, J., Sharma, S., Gansor, J., Senft, S., Weaner, B., ... \& Schmidt, R. (2008). Utility of the "surprise" question to identify dialysis patients with high mortality. Clinical Journal of the American Society of Nephrology, 3(5), 1379-1384.

Moss, A. H., Zive, D. M., Falkenstine, E. C., \& Dunithan, C. (2017). The quality of POLST completion to guide treatment: a 2-state study. Journal of the American Medical Directors Association, 18(9), 810-e5.

Murphy, P. W., Davis, T. C., Long, S. W., Jackson, R. H., \& Decker, B. C. (1993). Rapid estimate of adult literacy in medicine (REALM): a quick reading test for patients. Journal of Reading, 37(2), 124-130.

Nasreddine, Z., Phillips, N.A., Be'dirian, V., Charbonneau, S., Whitehead, V., Collin, I., y Chertkow, H. (2005). The Montreal Cognitive Assessment, MoCA: A brief screening tool for Mild Cognitive Impairment. Journal of American Geriatrics Society, 53(4), 695-699.

O’Connor, A. M., Wells, G. A., Tugwell, P., Laupacis, A., Elmslie, T., \& Drake, E. (1999). The effects of an "explicit” values clarification exercise in a woman's decision aid regarding postmenopausal hormone therapy. Health Expectations, 2(1), 21-32. http://doi.org/10.1046/j.1369-6513.1999.00027.x

O’Connor, A. M., (1994). Validation of a decisional conflict scale. Medical Decision Making : An International Journal of the Society for Medical Decision Making, 15(1), 25-30. http://doi.org/10.1177/0272989X9501500105 
O’Connor, A. M., Fiset, V., DeGrasse, C., Graham, I. D., Evans, W., Stacey, D., ... Tugwell, P. (1999). Decision aids for patients considering options affecting cancer outcomes: evidence of efficacy and policy implications. Journal of the National Cancer Institute. Monographs, 9(25), 67-80. Retrieved from http://www.ncbi.nlm.nih.gov/pubmed/10854460

Rahman, A. N., Bressette, M., \& Enguidanos, S. (2017). Quality of physician orders for lifesustaining treatment forms completed in nursing homes. Journal of palliative medicine, 20(5), 538-541.

Richardson, D. K., Fromme, E., Zive, D., Fu, R., \& Newgard, C. D. (2014). Concordance of outof-hospital and emergency department cardiac arrest resuscitation with documented end-oflife choices in Oregon. Annals of Emergency Medicine, 63(4), 375-383.

\section{http://dx.doi.org/10.1016/j.annemergmed.2013.09.004}

Schmidt, T. A., Hickman, S. E., Tolle, S. W., \& Brooks, H. S. (2004). The Physician Orders for Life-Sustaining Treatment program: Oregon emergency medical technicians’ practical experiences and attitudes. Journal of the American Geriatrics Society, 52(9), 1430-1434. http://doi.org/10.1111/j.1532-5415.2004.52403.x

Schwartz, L. M., Woloshin, S., Black, W. C., \& Welch, H. G. (1997). The role of numeracy in understanding the benefit of screening mammography. Annals of Internal Medicine, 127, 966-972.

Sepucha, K. R., Borkhoff, C. M., Lally, J., Levin, C. A., Matlock, D. D., Ng, C. J., ... Thomson, R. (2013). Establishing the effectiveness of patient decision aids: key constructs and measurement instruments. BMC Medical Informatics and Decision Making, 13 Suppl 2, S12. http://doi.org/10.1186/1472-6947-13-S2-S12

Shay, L. A., \& Lafata, J. E. (2015). Where is the evidence? A systematic review of shared 
decision making and patient outcomes. Medical Decision Making, 35(1), 114-131. DOI: $10.1177 / 0272989 X 14551638$

Simon, Herbert A. (1956). "Rational choice and the structure of the environment. Psychological Review. 63 (2): 129-138. doi: 10.1037/h0042769

Song, M. K., \& Sereika, S. M. (2006). An evaluation of the Decisional Conflict Scale for measuring the quality of end-of-life decision making. Patient Education and Counseling, 61(3), 397-404. http://doi.org/10.1016/j.pec.2005.05.003

Stacey, D., Légaré, F., Nf, C., Cl, B., Mj, B., Kb, E., ... Holmes-rovner, M. (2014). Decision aids for people facing health treatment or screening decisions. The Cochrane Database of Systematic Reviews. http://doi.org/10.1002/14651858.CD001431.pub4.Copyright

Stacey, D., Légaré, F., Lewis, K., Barry, M. J., Bennett, C. L., Eden, K. B., ... Trevena, L. (2017). Decision aids for people facing health treatment or screening decisions. Cochrane Database of Systematic Reviews. http://doi.org/10.1002/14651858.CD001431.pub5

Stolte, J. F. (1994). The context of satisficing in vignette research. The Journal of Social Psychology, 134, 727-733

Sugiyama, T., Zingmond, D., Lorenz, K. A., Diamant, A., O’Malley, K., Citko, J., ... Wenger, N. S. (2013). Implementing physician orders for life-sustaining treatment in California hospitals: factors associated with adoption. Journal of the American Geriatric Society, 61(8), 1337-1344. http://doi.org/10.1111/jgs.12367

Sundar, S., Do, J., \& O’Cathail, M. (2015). Misconceptions about 'do-not-resuscitate (DNR)'orders in the era of social media. Resuscitation, 86, e3. http://dx.doi.org/10.1016/j.resuscitation.2014.10.014 03

Tabachnick, B. G. \& Fidell, L. S. (Eds.). (2014). Using multivariate statistics. Pearson. 
Tolle, S. W., Tilden, V. P., Nelson, C. A., \& Dunn, P. M. (1998). A prospective study of the efficacy of the physician order form for life-sustaining treatment. Journal of the American Geriatric Society, 46(9), 1097-1102. Retrieved from

\section{http://www.ncbi.nlm.nih.gov/pubmed/9736102}

Torke, A. M., Alexander, G. C., \& Lantos, J. (2008). Substituted judgment: The limitations of autonomy in surrogate decision making. Journal of General Internal Medicine, 23(9), 15141517.

Ulrich, C. M., \& Ratcliffe, S. J. (2007). Hypothetical vignettes in empirical bioethics research. In L. Jacoby \& L. A. Siminoff (Eds.), Empirical Methods for Bioethics: A primer, (pp. 161181). JAI Press.

Pope, T. M., \& Hexum, M. (2012). Legal briefing: POLST: physician orders for life-sustaining treatment. J Clin Ethics, 23(4), 353-376. Retrieved from http://www.ncbi.nlm.nih.gov/pubmed/23469698

Rawson, K. A., Gunstad, J., Hughes, J., Spitznagel, M. B., Potter, V., Waechter, D., \& Rosneck, J. (2010). The METER: a brief, self-administered measure of health literacy. Journal of General Internal Medicine, 25(1), 67-71. DOI: 10.1007/s11606-009-1158-7

van Weert, J. C., Van Munster, B. C., Sanders, R., Spijker, R., Hooft, L., \& Jansen, J. (2016). Decision aids to help older people make health decisions: a systematic review and metaanalysis. BMC Medical Informatics and Decision Making, 16(1), 45. DOI 10.1186/s12911016-0281-8

Vo, H., Pekmezaris, R., Guzik, H., Nouryan, C., Patel, C., Vij, B., ... Wolf-Klein, G. (2011). Knowledge and attitudes of health care workers regarding MOLST (Medical Orders for Life-Sustaining Treatment) implementation in long-term care facilities. Geriatric Nursing, 
32(1), 58-62. http://doi.org/10.1016/j.gerinurse.2010.11.002

Volandes, A. E., Paasche-Orlow, M. K., Barry, M. J., Gillick, M. R., Minaker, K. L., Chang, Y., ... Mitchell, S. L. (2009). Video decision support tool for advance care planning in dementia: Randomised controlled trial. British Medical Journal, 338, b2159. http://doi.org/10.1136/bmj.b2159

Volandes, A. E., Ferguson, L. A., Davis, A. D., Hull, N. C., Green, M. J., Chang, Y., ... PaascheOrlow, M. K. (2011). Assessing end-of-life preferences for advanced dementia in rural patients using an educational video: A randomized controlled trial. Journal of Palliative Medicine, 14(2), 169-177. http://doi.org/10.1089/jpm.2010.0299

Volandes, A. E., Brandeis, G. H., Davis, A. D., Paasche-Orlow, M. K., Gillick, M. R., Chang, Y., ... Mitchell, S. L. (2012). A randomized controlled trial of a goals-of-care video for elderly patients admitted to skilled nursing facilities. Journal of Palliative Medicine, 15(7), 805-11. http://doi.org/10.1089/jpm.2011.0505

Volandes, A. E., Paasche-Orlow, M. K., Mitchell, S. L., El-Jawahri, A., Davis, A. D., Barry, M. J., ... Temel, J. S. (2013). Randomized controlled trial of a video decision support tool for cardiopulmonary resuscitation decision making in advanced cancer. Journal of Clinical Oncology, 31(3), 380-386. http://doi.org/10.1200/JCO.2012.43.9570

Weller, J. A., Dieckmann, N. F., Tusler, M., Mertz, C. K., Burns, W. J., \& Peters, E. (2013). Development and testing of an abbreviated numeracy scale: A Rasch analysis approach. Journal of Behavioral Decision Making, 26(2), 198-212. DOI: 10.1002/bdm Wenger, N. S., Citko, J., O’Malley, K., Diamant, A., Lorenz, K., Gonzalez, V., \& Tarn, D. M. (2013). Implementation of physician orders for life sustaining treatment in nursing homes in california: Evaluation of a novel statewide dissemination mechanism. Journal of General 
Internal Medicine, 28(1), 51-57. http://doi.org/10.1007/s11606-012-2178-2

Wills, C. E., \& Holmes-Rovner, M. (2003). Preliminary validation of the Satisfaction With Decision scale with depressed primary care patients. Health Expectations, 6(2), 149-159. http://doi.org/10.1046/j.1369-6513.2003.00220.x 


\section{Table 1}

Bivariate Correlations between Pre-Intervention Study Variables

\begin{tabular}{|c|c|c|c|c|c|c|c|c|c|c|c|c|}
\hline Variables & 1 & 2 & 3 & 4 & 5 & 6 & 7 & 8 & 9 & 10 & 11 & 12 \\
\hline $\begin{array}{l}\text { 1.CPR } \\
\text { Knowledge }\end{array}$ & 1 & .13 & $.26^{*}$ & .22 & .18 & .14 & .24 & .19 & .15 & .08 & .10 & .10 \\
\hline $\begin{array}{l}\text { 2.CPR } \\
\text { Conflict }\end{array}$ & .13 & 1 & $.66^{* *}$ & .24 & $.81 * *$ & $.73 *$ & -.10 & $.78 * *$ & $.71 * *$ & .24 & $.76 * *$ & $.73 * *$ \\
\hline $\begin{array}{l}\text { 3.CPR } \\
\text { Satisfaction }\end{array}$ & $.26 *$ & $.66^{* *}$ & 1 & .22 & $.77 * *$ & $.84 * *$ & -.14 & $.73 * *$ & $.74 * *$ & .09 & $.69 * *$ & $.73 * *$ \\
\hline $\begin{array}{l}\text { 4.MI } \\
\text { Knowledge }\end{array}$ & .22 & .24 & .22 & 1 & .21 & $.32 * *$ & .16 & $.33 * *$ & $.28 *$ & $.47 * *$ & $.35 * *$ & $.39 * *$ \\
\hline $\begin{array}{l}\text { 5.MI } \\
\text { Conflict }\end{array}$ & .18 & $.81 * *$ & $.77 * *$ & .21 & 1 & $.84 * *$ & -.15 & $.87 * *$ & $.79 * *$ & $.29 *$ & $.86^{* *}$ & $.82 * *$ \\
\hline $\begin{array}{l}\text { 6.MI } \\
\text { Satisfaction }\end{array}$ & .14 & $.73 * *$ & $.84 * *$ & $.32 * *$ & $.84 * *$ & 1 & -.20 & $.84 * *$ & $.84 * *$ & .20 & $.84 * *$ & $.80 * *$ \\
\hline $\begin{array}{l}\text { 7.IV } \\
\text { Knowledge }\end{array}$ & .24 & -.10 & -.14 & .16 & -.15 & -.20 & 1 & -.11 & -.13 & .21 & -.14 & -.13 \\
\hline $\begin{array}{l}\text { 8.IV } \\
\text { Conflict }\end{array}$ & .19 & $.78 * *$ & $.73 * *$ & $.33 * *$ & $.87 * *$ & $.84 * *$ & -.10 & 1 & $.93 * *$ & $.33 * *$ & $.85 * *$ & $.87 * *$ \\
\hline $\begin{array}{l}\text { 9.IV } \\
\text { Satisfaction }\end{array}$ & .15 & $.71 * *$ & $.74 * *$ & $.28 *$ & $.79 * *$ & $.84 * *$ & -.13 & $.93 * *$ & 1 & $.28 * *$ & $.81 * *$ & $.86^{* *}$ \\
\hline $\begin{array}{l}\text { 10.FT } \\
\text { Knowledge }\end{array}$ & .08 & .24 & .09 & $.47 * *$ & $.29 *$ & .20 & .21 & $.33 * *$ & $.28 *$ & 1 & $.25 *$ & $.32 * *$ \\
\hline $\begin{array}{l}\text { 11.FT } \\
\text { Conflict }\end{array}$ & .10 & $.76^{* *}$ & $.69 * *$ & $.35 * *$ & $.86 * *$ & $.84 * *$ & -.14 & $.85 * *$ & $.81 * *$ & $.25 *$ & 1 & $.84 * *$ \\
\hline $\begin{array}{l}\text { 12.FT } \\
\text { Satisfaction }\end{array}$ & .10 & $.73 * *$ & $.73 * *$ & $.39 * *$ & $.82 * *$ & $.80 * *$ & -.13 & $.87 * *$ & $.86^{* *}$ & $.32 * *$ & $.84 * *$ & 1 \\
\hline
\end{tabular}

$* p<.05, * * p<.01$. 


\section{Table 2}

Bivariate Correlations between Post-Intervention Study Variables

\begin{tabular}{|c|c|c|c|c|c|c|c|c|c|c|c|c|}
\hline Variables & 1 & 2 & 3 & 4 & 5 & 6 & 7 & 8 & 9 & 10 & 11 & 12 \\
\hline $\begin{array}{l}\text { 1.CPR } \\
\text { Knowledge }\end{array}$ & 1 & $.43 * *$ & $.31 *$ & $.45 * *$ & $.40 * *$ & $.35 * *$ & $.43 * *$ & $.36 * *$ & $.34 * *$ & .22 & $.38 * *$ & $.32 *$ \\
\hline $\begin{array}{l}\text { 2.CPR } \\
\text { Conflict }\end{array}$ & $.43 * *$ & 1 & $.93 * *$ & .24 & $.89 * *$ & $.86^{* *}$ & .13 & $.91 * *$ & $.84 * *$ & .21 & $.83 * *$ & $.76^{* *}$ \\
\hline $\begin{array}{l}\text { 3.CPR } \\
\text { Satisfaction }\end{array}$ & .31 & $.93 * *$ & 1 & .17 & $.87 * *$ & .92 & .06 & $.92 * *$ & $.91 * *$ & .22 & $.79 * *$ & $.81 * *$ \\
\hline $\begin{array}{l}\text { 4.MI } \\
\text { Knowledge }\end{array}$ & $.45 * *$ & .24 & .17 & 1 & $.35 * *$ & $.28 *$ & $.36 * *$ & $.32 * *$ & $.28 *$ & $.41 * *$ & $.36 * *$ & $.31 *$ \\
\hline $\begin{array}{l}\text { 5.MI } \\
\text { Conflict }\end{array}$ & $.40 * *$ & $.89 * *$ & $.87 * *$ & $.35 * *$ & 1 & $.92 * *$ & .15 & $.94 * *$ & $.89 * *$ & $.35 * *$ & $.92 * *$ & $.89 * *$ \\
\hline $\begin{array}{l}\text { 6.MI } \\
\text { Satisfaction }\end{array}$ & $.35 * *$ & $.86 * *$ & $.92 * *$ & $.28 *$ & $.92 * *$ & 1 & .09 & $.92 * *$ & $.96 * *$ & $.29 *$ & $.88 * *$ & $.92 * *$ \\
\hline $\begin{array}{l}\text { 7.IV } \\
\text { Knowledge }\end{array}$ & $.43 * *$ & .13 & .06 & $.36 * *$ & .15 & .09 & 1 & .10 & .10 & $.25^{*}$ & .23 & .11 \\
\hline $\begin{array}{l}\text { 8.IV } \\
\text { Conflict }\end{array}$ & $.36 * *$ & $.91 * *$ & $.92 * *$ & $.32 * *$ & $.94 * *$ & $.92 * *$ & .10 & 1 & $.92 * *$ & $.28 *$ & $.90 * *$ & $.85 * *$ \\
\hline $\begin{array}{l}\text { 9.IV } \\
\text { Satisfaction }\end{array}$ & $.34 * *$ & $.84 * *$ & $.91 * *$ & $.28 *$ & $.89 * *$ & $.96 * *$ & .10 & $.92 * *$ & 1 & $.31 *$ & $.90 * *$ & $.95 * *$ \\
\hline $\begin{array}{l}\text { 10.FT } \\
\text { Knowledge }\end{array}$ & .22 & .21 & .22 & $.41 * *$ & $.35 * *$ & $.29 *$ & $.25 *$ & $.28 *$ & $.31 *$ & 1 & $.36 * *$ & $.37 * *$ \\
\hline $\begin{array}{l}\text { 11.FT } \\
\text { Conflict }\end{array}$ & $.38 * *$ & $.83 * *$ & $.79 * *$ & $.36^{* *}$ & $.92 * *$ & $.88 * *$ & .23 & $.90 * *$ & $.90 * *$ & $.36 * *$ & 1 & $.91 * *$ \\
\hline $\begin{array}{l}\text { 12.FT } \\
\text { Satisfaction }\end{array}$ & $.32 *$ & $.76^{* *}$ & $.81 * *$ & $.31 *$ & $.89 * *$ & $.92 * *$ & .11 & $.85 * *$ & $.95 * *$ & $.37 * *$ & $.91 * *$ & 1 \\
\hline
\end{tabular}

${ }^{*} p<.05, * * p<.01$. 
Table 3

Results of T-Tests Comparing Participant Characteristics at Baseline

\begin{tabular}{llll} 
Variable & df & $\mathrm{t}$ & Sig \\
\hline Age & 62 & -1.50 & 0.883 \\
Sex & 62 & -0.20 & 0.845 \\
Race & 62 & 1.64 & 0.107 \\
Marital Status & 62 & 0.04 & 0.968 \\
Education & 62 & -1.44 & 0.154 \\
Work Status & 62 & 0.00 & 1.000 \\
Chronic Illness & 62 & 0.34 & 0.733 \\
Medical Procedures & 62 & 0.33 & 0.745 \\
AD 1 & 62 & 0.77 & 0.443 \\
AD 2 & 62 & -1.30 & 0.199 \\
DNR Card & 62 & 0.19 & 0.848 \\
WV POST & 62 & 0.32 & 0.751 \\
EoL decision-making & 30 & -.28 & 0.781 \\
Health Status & 62 & -0.11 & 0.911 \\
\hline
\end{tabular}




\section{Table 4}

Demographic Information $(n=64)$

\begin{tabular}{|c|c|c|c|c|}
\hline \multirow[b]{2}{*}{ Characteristic } & \multicolumn{2}{|c|}{$\begin{array}{l}\text { Control } \\
\text { Group } \\
(\mathrm{n}=28)\end{array}$} & \multicolumn{2}{|c|}{$\begin{array}{c}\text { Intervention } \\
\text { Group } \\
(\mathrm{n}=36)\end{array}$} \\
\hline & $\mathrm{N}$ & $\%$ & $\mathrm{~N}$ & $\%$ \\
\hline \multicolumn{5}{|l|}{ Sex } \\
\hline Male & 10 & 36 & 12 & 33 \\
\hline Female & 18 & 64 & 24 & 67 \\
\hline \multicolumn{5}{|l|}{ Race } \\
\hline White & 26 & 93 & 36 & 100 \\
\hline African-American & 2 & 7 & - & - \\
\hline \multicolumn{5}{|l|}{ Marital status } \\
\hline Single & 3 & 11 & 4 & 11 \\
\hline Married & 15 & 54 & 22 & 61 \\
\hline Live-in partner & 1 & 4 & - & - \\
\hline Divorced & 5 & 18 & 7 & 19 \\
\hline Widowed & 1 & 4 & 3 & 8 \\
\hline \multicolumn{5}{|l|}{ Occupation status } \\
\hline Working full-time & 13 & 46 & 17 & 47 \\
\hline Working part-time & 2 & 7 & 4 & 11 \\
\hline Retired & 13 & 46 & 13 & 36 \\
\hline Other & - & - & 2 & 6 \\
\hline \multicolumn{5}{|l|}{ Chronic illness } \\
\hline Yes & 12 & 43 & 17 & 47 \\
\hline No & 16 & 57 & 19 & 53 \\
\hline \multicolumn{5}{|c|}{ Life-threatening procedure } \\
\hline Yes & 9 & 32 & 13 & 36 \\
\hline No & 19 & 68 & 23 & 64 \\
\hline \multicolumn{5}{|l|}{ Advance directive } \\
\hline Living will & 19 & 68 & 21 & 58 \\
\hline MPOA & 15 & 54 & 25 & 70 \\
\hline \multicolumn{5}{|l|}{ Medical order } \\
\hline DNR order & 6 & 24 & 7 & 19 \\
\hline POST & 3 & 10 & 3 & 8 \\
\hline \multicolumn{5}{|c|}{ End-of-Life Decision-making } \\
\hline Yes & 15 & 54 & 18 & 50 \\
\hline No & 13 & 46 & 18 & 50 \\
\hline \multicolumn{5}{|l|}{ Physical Health } \\
\hline Excellent & 8 & 29 & 8 & 22 \\
\hline Very good & 9 & 32 & 14 & 39 \\
\hline Good & 7 & 25 & 10 & 28 \\
\hline Fair & 4 & 14 & 4 & 11 \\
\hline
\end{tabular}




\section{Table 5}

Means and Standard Deviations for All Outcome Variables

\begin{tabular}{|c|c|c|}
\hline & $\begin{array}{l}\text { Control Group } \\
(\mathrm{n}=28)\end{array}$ & $\begin{array}{l}\text { Intervention Group } \\
(\mathrm{n}=36)\end{array}$ \\
\hline Variable & $\mathrm{M}(\mathrm{SD})$ & $\mathrm{M}(\mathrm{SD})$ \\
\hline Pre-test CPR & $2.14(1.15)$ & $1.72(1.06)$ \\
\hline \multicolumn{3}{|l|}{ Knowledge } \\
\hline Pre-test MI & $5.36(.99)$ & $5.11(1.21)$ \\
\hline \multicolumn{3}{|l|}{ Knowledge } \\
\hline Pre-test IV & $2.89(.79)$ & $2.75(.77)$ \\
\hline \multicolumn{3}{|l|}{ Knowledge } \\
\hline Pre-test N & $2.96(.88)$ & $2.69(.86)$ \\
\hline \multicolumn{3}{|l|}{ Knowledge } \\
\hline Pre-test CPR DCS & $22.32(6.16)$ & $21.75(5.68)$ \\
\hline Pre-test MI DCS & $22.11(5.20)$ & $20.83(5.19)$ \\
\hline Pre-test IV DCS & $22.75(5.05)$ & $22.42(5.35)$ \\
\hline Pre-test N DCS & $22.25(5.20)$ & $21.89(5.71)$ \\
\hline Pre-test CPR SWD & $24.25(4.35)$ & $23.86(3.67)$ \\
\hline Pre-test MI SWD & $23.79(4.11)$ & $23.08(4.35)$ \\
\hline Pre-test IV SWD & $23.46(3.96)$ & $23.36(5.11)$ \\
\hline Pre-test N SWD & $23.46(4.48)$ & $22.83(4.96)$ \\
\hline Post-test CPR & $2.25(1.00)$ & $3.69(1.09)$ \\
\hline \multicolumn{3}{|l|}{ Knowledge } \\
\hline Post-test MI & $5.25(1.27)$ & $6.17(1.03)$ \\
\hline \multicolumn{3}{|l|}{ Knowledge } \\
\hline Post-test IV & $2.86(.97)$ & $3.67(.59)$ \\
\hline \multicolumn{3}{|l|}{ Knowledge } \\
\hline Post-test N & $3.18(.91)$ & $3.31(.71)$ \\
\hline \multicolumn{3}{|l|}{ Knowledge } \\
\hline Post-test CPR DCS & $22.50(5.70)$ & $25.22(3.69)$ \\
\hline Post-test MI DCS & $22.18(5.19)$ & $24.86(3.64)$ \\
\hline Post-test IV DCS & $22.86(5.16)$ & $24.89(3.81)$ \\
\hline Post-test N DCS & $22.18(5.26)$ & $24.78(3.52)$ \\
\hline Post-test CPR SWD & $23.68(4.96)$ & $25.17(3.71)$ \\
\hline Post-test MI SWD & $23.50(4.72)$ & $25.25(3.27)$ \\
\hline Post-test IV SWD & $23.43(4.71)$ & $24.94(3.22)$ \\
\hline Post-test N SWD & $23.36(4.86)$ & $24.94(3.35)$ \\
\hline
\end{tabular}


Table 5

Multivariate Results of MANCOVA Examining CPR Knowledge and Decisional Conflict

\begin{tabular}{lllll}
\hline Effect & Wilk's $\Lambda$ & df & $F$ & $\eta_{\mathrm{p}}{ }^{2}$ \\
\hline $\begin{array}{l}\text { Numeracy } \\
\text { Pre-Intervention }\end{array}$ & 0.99 & 2,58 & 0.04 & .01 \\
$\begin{array}{l}\text { Knowledge } \\
\text { Pre-Intervention }\end{array}$ & 0.45 & 2,58 & $7.30^{* *}$ & .20 \\
$\begin{array}{l}\text { Conflict } \\
\text { Treatment Group }\end{array}$ & 0.55 & 2,58 & $36.08^{* * *}$ & .55 \\
\hline
\end{tabular}

$* p<.05, * * p<.01, * * * p<.001$. 
Table 6

Univariate F Tests for CPR Knowledge and Decisional Conflict at Post-Intervention

\begin{tabular}{|c|c|c|c|c|c|c|c|}
\hline \multirow[b]{2}{*}{ Outcome } & \multicolumn{2}{|c|}{ Control Group } & \multicolumn{2}{|c|}{ Intervention Group } & \multirow[b]{2}{*}{$F$} & \multirow[b]{2}{*}{$95 \% \mathrm{CI}$} & \multirow[b]{2}{*}{$\eta_{\mathrm{p}}{ }^{2}$} \\
\hline & Mean & SD & Mean & SD & & & \\
\hline Knowledge & 2.25 & 1.01 & 3.69 & 1.09 & $42.84 * * *$ & {$[-2.13,-1.13]$} & .42 \\
\hline $\begin{array}{l}\text { Decisional } \\
\text { Conflict }\end{array}$ & 22.50 & 5.70 & 25.22 & 3.69 & $17.89 * * *$ & {$[-5.00,-1.79]$} & .23 \\
\hline
\end{tabular}

${ }^{*} p<.05, * * p<.01, * * * p<.001$. 
Table 7

Results of ANCOVA for CPR Satisfaction with Decision at Post-Intervention

\begin{tabular}{|c|c|c|c|c|c|c|c|}
\hline \multirow[b]{2}{*}{ Outcome } & \multicolumn{2}{|c|}{ Control Group } & \multicolumn{2}{|c|}{ Intervention Group } & \multirow[b]{2}{*}{$F$} & \multirow[b]{2}{*}{$95 \% \mathrm{CI}$} & \multirow[b]{2}{*}{$\eta_{\mathrm{p}}^{2}$} \\
\hline & Mean & SD & Mean & SD & & & \\
\hline Satisfaction & 23.68 & 4.96 & 25.17 & 3.72 & $7.96 * *$ & {$[-3.05,-0.52]$} & .12 \\
\hline
\end{tabular}


Table 8

Multivariate Results of MANCOVA Examining Medical Interventions Knowledge and Decisional Conflict

\begin{tabular}{lllll}
\hline Effect & Wilk's $\Lambda$ & $\mathrm{df}$ & $F$ & $\eta_{\mathrm{p}}{ }^{2}$ \\
\hline $\begin{array}{l}\text { Numeracy } \\
\text { Pre-Intervention }\end{array}$ & 0.96 & 2,58 & 1.09 & .04 \\
$\begin{array}{l}\text { Knowledge } \\
\text { Pre-Intervention }\end{array}$ & 0.44 & 2,58 & $19.24 * * *$ & .40 \\
$\begin{array}{l}\text { Conflict } \\
\text { Treatment Group }\end{array}$ & 0.54 & 2,58 & $36.61 * * *$ & .56 \\
\hline
\end{tabular}

${ }^{*} p<.05, * * p<.01, * * * p<.001$. 
Table 9

Univariate F Tests for Medical Interventions Knowledge and Decisional Conflict at PostIntervention

\begin{tabular}{|c|c|c|c|c|c|c|c|}
\hline \multirow[b]{2}{*}{ Outcome } & \multicolumn{2}{|c|}{ Control Group } & \multicolumn{2}{|c|}{ Intervention Group } & \multirow[b]{2}{*}{$F$} & \multirow[b]{2}{*}{$95 \% \mathrm{CI}$} & \multirow[b]{2}{*}{$\eta_{\mathrm{p}}^{2}$} \\
\hline & Mean & SD & Mean & SD & & & \\
\hline Knowledge & 5.25 & 1.27 & 6.17 & 1.03 & $20.48 * * *$ & {$[-1.53,-0.59]$} & .26 \\
\hline $\begin{array}{l}\text { Decisional } \\
\text { Conflict }\end{array}$ & 22.18 & 5.19 & 24.86 & 3.64 & $31.02 * * *$ & {$[-5.17,-2.44]$} & .35 \\
\hline
\end{tabular}

${ }^{*} p<.05,{ }^{* *} p<.01, * * * p<.001$. 
Table 10

Results of ANCOVA for Medical Interventions Satisfaction with Decision at Post-Intervention

\begin{tabular}{llllllll}
\hline \multirow{2}{*}{ Outcome } & \multicolumn{5}{l}{ Control Group } & \multicolumn{4}{l}{ Intervention Group } & & \\
\cline { 2 - 5 } & Mean & SD & Mean & SD & $F$ & $95 \%$ CI & $\eta_{\mathrm{p}}{ }^{2}$ \\
Satisfaction & 23.50 & 4.72 & 25.25 & 3.28 & $14.72^{* * *}$ & {$[-3.50,-1.10]$} & .20 \\
\hline
\end{tabular}

${ }^{*} p<.05, * * p<.01, * * * p<.001$. 


\section{Table 11}

Multivariate Results of MANCOVA Examining IV Fluids Knowledge and Decisional Conflict

\begin{tabular}{lllll}
\hline Effect & Wilk's $\Lambda$ & df & $F$ & $\eta_{\mathrm{p}}{ }^{2}$ \\
\hline Numeracy & 0.99 & 2,58 & 0.07 & .02 \\
$\begin{array}{l}\text { Pre-Intervention } \\
\text { Knowledge }\end{array}$ & 0.63 & 2,58 & $17.33^{* * *}$ & .37 \\
$\begin{array}{l}\text { Pre-Intervention } \\
\text { Conflict }\end{array}$ & 0.31 & 2,58 & $65.72^{* * *}$ & .69 \\
Treatment Group & 0.52 & 2,58 & $27.01 * * *$ & .48 \\
\hline
\end{tabular}

${ }^{*} p<.05, * * p<.01, * * * p<.001$. 
Table 12

Univariate F Tests for IV Fluids Knowledge and Decisional Conflict at Post-Intervention

\begin{tabular}{lllllllll} 
& \multicolumn{7}{l}{ Control Group } & \multicolumn{6}{l}{ Intervention Group } & & \\
Outcome & Mean & SD & Mean & SD & $F$ & $95 \%$ CI & $\eta_{\mathrm{p}}{ }^{2}$ \\
& & & & & & & & \\
Knowledge & 2.86 & 0.97 & 3.67 & 0.59 & $31.00^{* * *}$ & {$[-1.26,-0.58]$} & .34 \\
$\begin{array}{l}\text { Decisional } \\
\text { Conflict }\end{array}$ & 22.86 & 5.16 & 24.89 & 3.81 & $11.72^{* *}$ & {$[-3.67,-0.96]$} & .17 \\
\hline
\end{tabular}

${ }^{*} p<.05, * * p<.01, * * * p<.001$. 
Table 13

Results of ANCOVA for IV Fluids Satisfaction with Decision at Post-Intervention

\begin{tabular}{llllllll}
\hline \multirow{2}{*}{ Outcome } & \multicolumn{6}{l}{ Control Group } & \multicolumn{4}{l}{ Intervention Group } & & \\
\cline { 2 - 5 } & Mean & SD & Mean & SD & $F$ & $95 \%$ CI & $\eta_{\mathrm{p}}{ }^{2}$ \\
Satisfaction & 23.43 & 4.71 & 24.94 & 3.22 & $6.38^{*}$ & {$[-2.90,-0.34]$} & .10 \\
\hline
\end{tabular}

${ }^{*} p<.05,{ }^{* *} p<.01, * * * p<.001$. 
Table 14

Multivariate Results of MANCOVA Examining Feeding Tube Knowledge and Decisional Conflict

\begin{tabular}{lllll}
\hline Effect & Wilk's $\Lambda$ & df & $F$ & $\eta_{\mathrm{p}}{ }^{2}$ \\
\hline Numeracy & 0.99 & 2,58 & 0.05 & .00 \\
$\begin{array}{l}\text { Pre-Intervention } \\
\text { Knowledge }\end{array}$ & 0.79 & 2,58 & $7.93^{* *}$ & .22 \\
$\begin{array}{l}\text { Pre-Intervention } \\
\text { Conflict }\end{array}$ & 0.42 & 2,58 & $39.34^{* * *}$ & .58 \\
Treatment Group & 0.78 & 2,58 & $8.16^{* *}$ & .22 \\
\hline
\end{tabular}

${ }^{*} p<.05, * * p<.01, * * * p<.001$. 


\section{Table 15}

Univariate F Tests for Feeding Tube Knowledge and Decisional Conflict at Post-Intervention

\begin{tabular}{|c|c|c|c|c|c|c|c|}
\hline \multirow[b]{2}{*}{ Outcome } & \multicolumn{2}{|c|}{ Control Group } & \multicolumn{2}{|c|}{ Intervention Group } & \multirow[b]{2}{*}{$F$} & \multirow[b]{2}{*}{$95 \% \mathrm{CI}$} & \multirow[b]{2}{*}{$\eta_{p}^{2}$} \\
\hline & Mean & SD & Mean & SD & & & \\
\hline Knowledge & 3.18 & 0.91 & 3.31 & 0.71 & 1.91 & {$[-0.61,0.11]$} & .03 \\
\hline $\begin{array}{l}\text { Decisional } \\
\text { Conflict }\end{array}$ & 22.18 & 5.26 & 24.78 & 3,52 & $16.41 * * *$ & {$[-4.39,-1.49]$} & .22 \\
\hline
\end{tabular}




\section{Table 16}

Results of ANCOVA for Feeding Tube Satisfaction with Decision at Post-Intervention

\begin{tabular}{llllllll} 
& \multicolumn{5}{l}{ Control Group } & \multicolumn{4}{l}{ Intervention Group } & & \\
Outcome & Mean & SD & Mean & SD & $F$ & $95 \%$ CI & $\eta_{\mathrm{p}}{ }^{2}$ \\
Syatisfaction & 23.36 & 4.86 & 24.94 & 3.35 & $12.81^{*}$ & {$[-3.15,-0.89]$} & .18 \\
\hline
\end{tabular}

${ }^{*} p<.05, * * p<.01, * * * p<.001$. 
Table 17

Binary Logistic Regression Predicting Post-Intervention CPR Decision

\begin{tabular}{lcccc}
\hline & $\mathrm{B}$ & S.E. & Wald $\chi^{2}$ & OR \\
\hline $\begin{array}{l}\text { Treatment } \\
\begin{array}{l}\text { Condition } \\
\text { Pre-Intervention } \\
\text { Decision }\end{array}\end{array}$ & 0.41 & 0.59 & 0.50 & 1.51 \\
\hline$* p<.05, * * p<.01, * * * p<.001$. & 0.63 & $11.97 * *$ & 8.92 \\
\end{tabular}


Table 18

Multinomial Logistic Regression Predicting Post-Intervention Medical Interventions Decision

$\begin{array}{llll}\text { B } & \text { S.E. } & \text { Wald } \chi^{2} & \text { OR }\end{array}$

Limited Interventions

Intervention Condition

$-1.03$

0.72

2.04

0.36

Full Interventions

Intervention Condition $\quad-1.90$

1.09

3,06

0.15

Note. Reference category is Comfort Measures

$* p<.05, * * p<.01, * * * p<.001$. 


\section{Table 19}

Binary Logistic Regression Predicting Post-Intervention IV Fluids Decision

\begin{tabular}{|c|c|c|c|c|}
\hline & B & S.E. & Wald $\chi^{2}$ & OR \\
\hline $\begin{array}{l}\text { Treatment } \\
\text { Condition }\end{array}$ & 0.50 & 0.72 & 0.49 & 1.65 \\
\hline $\begin{array}{l}\text { Pre-Intervention } \\
\text { Decision }\end{array}$ & 3.32 & 0.84 & $15.77 * * *$ & 27.73 \\
\hline
\end{tabular}


Table 20

Binary Logistic Regression Predicting Post-Intervention Feeding Tube Decision

\begin{tabular}{lcccc}
\hline & $\mathrm{B}$ & S.E. & Wald $\chi^{2}$ & OR \\
\hline $\begin{array}{l}\text { Treatment } \\
\begin{array}{l}\text { Condition } \\
\text { Pre-Intervention }\end{array}\end{array}$ & -0.39 & 0.68 & 0.32 & .680 \\
$\begin{array}{l}\text { Decision } \\
* p<.05, * * p<.01, * * * p<.001 .\end{array}$ & 0.81 & $9.39 * *$ & 11.94 \\
\end{tabular}


Table 21

Participant Responses to Aid Evaluation Questionnaire

\begin{tabular}{|c|c|c|c|c|c|}
\hline & Strongly & Disagree & Neither Agree & Agree & Strongly \\
\hline & Disagree & & or Disagree & & Agree \\
\hline $\begin{array}{l}\text { The video aid makes clear the } \\
\text { decisions to be made }\end{array}$ & $2.8 \%$ & - & $5.6 \%$ & $61.1 \%$ & $30.6 \%$ \\
\hline $\begin{array}{l}\text { The video aid presents an } \\
\text { alternative option for each } \\
\text { decision }\end{array}$ & - & $5.6 \%$ & $2.8 \%$ & $55.6 \%$ & $36.1 \%$ \\
\hline $\begin{array}{l}\text { The video aid provides } \\
\text { risks/benefits associated with } \\
\text { alternative options }\end{array}$ & - & $5.6 \%$ & $5.6 \%$ & $55.6 \%$ & $33.3 \%$ \\
\hline $\begin{array}{l}\text { The video aid provided } \\
\text { probabilities of outcomes } \\
\text { associated with treatment options }\end{array}$ & - & $2.8 \%$ & $2.8 \%$ & $61.1 \%$ & $33.3 \%$ \\
\hline $\begin{array}{l}\text { The video aid helped to clarify } \\
\text { personal values that influence the } \\
\text { decisions }\end{array}$ & $2.8 \%$ & $13.9 \%$ & $22.2 \%$ & $44.4 \%$ & $16.7 \%$ \\
\hline $\begin{array}{l}\text { The video aid appeared to be } \\
\text { biased or slanted toward a } \\
\text { particular option }\end{array}$ & $22.2 \%$ & $50 \%$ & $16.7 \%$ & $11.1 \%$ & - \\
\hline The video aid was helpful & - & - & $11.1 \%$ & $47.2 \%$ & $41.7 \%$ \\
\hline $\begin{array}{l}\text { I would recommend the video aid } \\
\text { to a friend or family member }\end{array}$ & - & - & $5.6 \%$ & $44.4 \%$ & $50 \%$ \\
\hline $\begin{array}{l}\text { Overall, I felt comfortable using } \\
\text { the video aid }\end{array}$ & - & - & $2.8 \%$ & $58.3 \%$ & $38.9 \%$ \\
\hline
\end{tabular}




\section{Appendix}

The following measures and materials included in the Appendix were utilized in the study:

Demographics Questionnaire, Clinical Vignette, Post leaflet, Knowledge Questionnaire, Evaluation of Aid Questionnaire, Aid Script. Additional analyses also included. 


\section{Additional Analyses}

\section{Research Questions 1-3 (CPR)}

A modified one-way MANCOVA analysis was conducted to examine the effect of the intervention on post-intervention ratings of knowledge and decisional conflict for the CPR decision, using numeracy as a covariate. A significant main effect of the intervention was found, $\mathrm{F}(2,60)=14.11, \mathrm{p}<.001$, partial $\eta 2=.32$. Based on follow-up univariate $F$ tests, participants who viewed the aid were more knowledgeable about $\mathrm{CPR} F(1,61)=31.98, \mathrm{p}<.001$, partial $\eta 2=$ .32 , at post-intervention compared to those who did not view the aid. There were no significant differences found for decisional conflict.

\section{Research Questions 4-6 (medical interventions)}

A modified one-way MANCOVA analysis was conducted to examine the effect of the intervention on post-intervention ratings of knowledge and decisional conflict for the medical interventions decision, using numeracy as a covariate. A significant main effect of the intervention was found for medical interventions $\mathrm{F}(2,60)=5.91, \mathrm{p}=.005$, partial $\eta 2=.17$. Based on follow-up univariate $F$ tests, participants who viewed the aid were more knowledgeable about medical interventions $\mathrm{F}(1,61)=9.39, \mathrm{p}=.003$, partial $\eta 2=.13$, and had less decisional conflict $\mathrm{F}(1,61)=6.04, \mathrm{p}=.017$, partial $\eta 2=.09$ at post-intervention compared to those who did not view the aid.

\section{Research Questions 7-9 (IV fluids)}

A modified one-way MANCOVA analysis was conducted to examine the effect of the intervention on post-intervention ratings of knowledge and decisional conflict for the IV fluids decision, using numeracy as a covariate. A significant main effect of the intervention found for IV fluids $\mathrm{F}(2,60)=9.63, \mathrm{p}<.001$, partial $\eta 2=.24$. Based on follow-up univariate $F$ tests, 
participants who viewed the aid were more significantly more knowledgeable about IV fluids $\mathrm{F}(1,61)=16.27, \mathrm{p}<.001$, partial $\eta 2=.21$, at post-intervention compared to those who did not view the aid. There were no significant differences found for decisional conflict.

\section{Research Questions 10-12 (nutrition)}

A modified one-way MANCOVA analysis was conducted to examine the effect of the intervention on post-intervention ratings of knowledge and decisional conflict for the nutrition decision, using numeracy as a covariate. There was no significant main effect of the intervention found for nutrition $\mathrm{F}(3,59)=2.61, \mathrm{p}=.060$, partial $\eta 2=.12$.

\section{Conclusions}

Results from the additional analyses suggest potential suppression effects. The inclusion of pre-intervention ratings as covariates in the original analyses may have accounted for the relative stability of participant responses from pre- to post-intervention, resulting in the identification of significant differences at post-intervention. Conclusions should be drawn about the current study only after considering the potential suppression effects. 
Demographics Questionnaire

This next section will ask you general questions about yourself.

1. What is your age?

2. What is your biological sex?
a. Male
b. Female

3. What is your race or ethnic background? (please choose one):
a. White/Caucasian (not Hispanic)
b. Black/African-American
c. Asian-American
d. Hispanic
e. Native American
f. Pacific Islander
g. Other:

4. What is your marital status?
a. Single
b. Married
c. Live-in partner
d. Separated
e. Divorced
f. Widowed

5. How many years of education have you completed?

6. What is your current job or occupation status?
a. Working full time (for income or as volunteer)
b. Working part time (for income or as volunteer)
c. Retired
d. Other:

7. Do you have any current chronic medical illness? (cancer, arthritis, hypertension, etc.)
a. Yes
b. No

8. Please describe the illnesses if you selected "Yes" as your answer for the previous question

9. Have you had any major medical procedures performed in the last 20 years? (organ transplant, chemotherapy, joint replacement, dialysis, etc.)

a. Yes 
b. No

10. Please describe if you selected "Yes" to the previous question.

11. Do you currently have advance directives? (Check all that apply)

$\square$ Living will

Medical power of attorney

12. Do you have a medical order? (Check all that apply)

$\square$ Do Not Resuscitate card

Physician Order for Scope of Treatment

13. Have you been faced with making decisions for yourself or for a friend/family member, regarding CPR, life support, mechanical ventilation, feeding tubes, IV fluids?
a. Yes
b. No

14. In general, would you say your physical health is
a. Excellent
b. Very good
c. Good
d. Fair
e. Poor 


\section{Clinical Vignette}

The following information is hypothetical. The information should be considered when making a treatment decision.

You are currently 75 years old and have diagnoses of Chronic Obstructive Pulmonary Disease (COPD) and Stage 4 lung cancer. Your COPD causes shortness of breath, wheezing at times, and a chronic cough. For the past 6 months you have been receiving treatment at WVU Medicine for Stage 4 lung cancer. You have just learned that the cancer has metastasized and has spread to other areas of your body. There is no further chemotherapy or radiation therapy that is likely to benefit you. You sought a second opinion from a specialist in Pittsburgh who also believed further treatments will not cure your cancer. Your oncologist suggested that you get your affairs in order and "look into" hospice. When asked, your physician said that she thought your estimated prognosis was one year or less. You talked about your situation with a neighbor who is a nurse. Your neighbor suggests that you complete a POST form so that your wishes for treatment are known and respected. Your physician agreed that it was appropriate for you to complete a POST form. Your physician asked you what your preferences were for orders on the POST form. 


\section{Physician Orders for Scope of Treatment (POST)}

The POST is a medical order form intended for people with serious health conditions. It is used to inform other providers about your treatment wishes.

Section A provides orders regarding cardiopulmonary resuscitation (CPR).

Section B of the POST contains choices regarding how aggressive you want your medical treatment to be. There are three options to choose from. The three levels are: Full Interventions, Limited Additional Interventions, and Comfort Measures.

Full Interventions involves all measures to keep you alive including use of CPR and a breathing machine in an intensive care unit. Limited additional interventions include intravenous fluids and heart monitoring but not intensive care. Patients will not receive CPR with this order. Comfort measures include treatments to preserve patient dignity without the use of machines. Patients with a comfort measures order will usually be kept comfortable at home or in a nursing home. They will not be transferred to the hospital unless they cannot be kept comfortable where they live.

Section $\mathrm{C}$ provides choices regarding medically administered fluids and nutrition through an intravenous line or tube. It gives the choices of no fluids or nutrition through a tube, fluids only for a period of time, or nutrition for the rest of your life. 


\section{Knowledge Questionnaire}

Please circle the answer you think is correct. If you are not sure of an answer, please make an educated guess but do not guess randomly.

1. During CPR, about how many times is the person's chest pushed in each minute?
a. $100-120$
b. $80-100$
c. $60-80$
d. Don't know/Not sure

2. What percent of older adults $(65+)$ are discharged from the hospital after receiving CPR?
a. More than $90 \%$
b. About $50 \%$
c. Less than $20 \%$
d. Don't know/Not sure

3. What percent of people with late stage cancers recover from CPR and are discharged from the hospital?
a. About $50 \%$
b. About $30 \%$
c. Less than $10 \%$
d. Don't know/Not sure

4. What percentage of people have brain damage after being resuscitated using CPR?
a. About $50 \%$
b. About 30\%
c. Less than $10 \%$
d. Don't know/Not sure

5. What medical procedure is used when a person is unconscious or unable to breathe on his or her own?
a. Cardioversion
b. Mechanical ventilation
c. Atrial defibrilation
d. Don't know/Not sure

6. What is the default level of care for all West Virginians if they have not completed other orders for end of life care?
a. Full Interventions
b. Limited Additional Interventions
c. Comfort Measures
d. Don't know/Not sure

7. What is the "treatment plan" for people who select Limited Additional Interventions?

a. Provide full treatments including life support measures in the intensive care unit

b. Maximize comfort through symptom management

c. Provide basic medical treatments

d. Don't know/Not sure

8. Individuals who select are more likely THAN THOSE WHO SELECT OTHER OPTIONS to die outside of the hospital (e.g., home, nursing facility, assisted living). 

a. Full Interventions
b. Limited Additional Interventions
c. Comfort Measures
d. Don't know/Not sure

9. Which medical intervention order allows for use of intubation and mechanical ventilation?
a. Full Interventions
b. Limited Additional Interventions
c. Comfort Measures
d. Don't know/Not sure

10. What does IV stand for?
a. Intravena
b. Intravagal
c. Intravenous
d. Don't know/Not sure

11. About how often should an IV be moved from one part of the skin to another to prevent skin irritation or infection?
a. Every day
b. Every 3-5 days
c. Once a week
d. It does not need to be moved
e. Don't know/Not sure

12. Is it natural near the end-of-life for the body to become less able to take in water and salt?
a. Yes
b. No
c. Don't know/Not sure

13. What is aspiration?

a. The increase of white blood cells to fight infection

b. The increase of red blood cells to bring more oxygen to the lungs

c. When food or liquid get into the lungs

d. Don't know/Not sure

14. What can aspiration lead to?

a. Low blood pressure

b. Pneumonia

c. Intramural infection

d. Don't know/Not sure

15. Has the use of feeding tubes been shown to reliably extend a terminally ill patient's life?

a. True

b. False

c. Don't know/Not sure

16. Based on the intervention level you selected, would CPR be administered if your heart stopped beating?
a. Yes
b. No
c. Don't know/Not sure 
17. Based on the intervention level you selected, would mechanical ventilation be used if you had difficulty breathing?
a. Yes
b. No
c. Don't know/Not sure

18. Based on the intervention level you selected, would you receive any treatment that had a goal to extend your life?
a. Yes
b. No
c. Don't know/Not sure

19. Based on the intervention level you selected, would you receive nutrition through tubes if you had problems eating and weight loss?
a. Yes
b. No
c. Don't know/Not sure

20. Based on the intervention level you selected, would you receive fluids through an IV line if you had problems drinking?
a. Yes
b. No
c. Don't know/Not sure 


\section{Evaluation of Video Aid Questionnaire}

\begin{tabular}{|l|l|l|l|l|l|}
\hline & $\begin{array}{l}\text { Strongly } \\
\text { Agree }\end{array}$ & Agree & $\begin{array}{l}\text { Neither } \\
\text { Agree or } \\
\text { Disagree }\end{array}$ & Disagree & $\begin{array}{l}\text { Strongly } \\
\text { Disagree }\end{array}$ \\
\hline $\begin{array}{l}\text { The video aid makes clear the } \\
\text { decisions to be made }\end{array}$ & & & & & \\
\hline $\begin{array}{l}\text { The video aid presents an alternative } \\
\text { option for each decision }\end{array}$ & & & & & \\
\hline $\begin{array}{l}\text { The video aid provides risks/benefits } \\
\text { associated with alternative options } \\
\text { of outcomes associated with treatment } \\
\text { options }\end{array}$ & & & & & \\
\hline $\begin{array}{l}\text { The video aid helped to clarify } \\
\text { personal values that influence the } \\
\text { decisions }\end{array}$ & & & & & \\
\hline $\begin{array}{l}\text { The video aid did not appear to be } \\
\text { biased or slanted toward any } \\
\text { particular option }\end{array}$ & & & & & \\
\hline The video aid was helpful & & & & & \\
\hline $\begin{array}{l}\text { I would recommend the video aid to a } \\
\text { friend or family member }\end{array}$ & & & & & \\
\hline $\begin{array}{l}\text { Overall, I felt comfortable using the } \\
\text { video aid }\end{array}$ & & & & & \\
\hline
\end{tabular}




\begin{abstract}
Aid Script
The Physician Orders for Scope of Treatment, which is called the POST form was designed to help patients with an advanced illness express their wishes for medical treatments they want near the end-of-life. Patients or appointed decision-makers should consult with a physician or nurse practitioner to consider whether a POST is right for them. The purpose of the video is to provide information about the sections of the POST form and information about medical treatments the patient or appointed decision-maker should consider when completing a POST form.
\end{abstract}

\title{
$\underline{\text { Section A }}$
}

Section A provides two choices for what treatments a person would want if his or her heart stopped beating, also known as cardiac arrest. During cardiac arrest, a person has no pulse and is not breathing. The choices are: Attempt Resuscitation/CPR or Do Not Attempt Resuscitation/DNR.

"What is CPR?"

Cardiopulmonary Resuscitation (CPR) involves pressing a person's breastbone down 2 to 2.5 inches into the chest, 100-120 times a minute. Chest compressions are done to try to keep blood flow to the brain until a heartbeat returns. In addition, medications or electric shocks are given to try to restart the heart.

\section{"Does CPR work?"}

Eighteen percent of older adults (65+ years) survive to be sent home from the hospital after having CPR. About 10\% of elderly with serious illness or older adults who have CPR outside of the hospital survive. Fewer than $10 \%$ of older adults or people with advanced illness who survive cardiac arrest are still alive one year later.

"What are the risks of having CPR?"

The primary reason people do not survive CPR is due to lack of oxygen in the brain during cardiac arrest. Brain damage can start to occur after 4 minutes without oxygen. Up to $50 \%$ of people who survive CPR have brain damage. Due to the force used during CPR chest compressions, $33 \%$ of survivors have a broken breastbone or ribs.

"What are the benefits of having CPR?"

CPR offers a chance of being kept alive by providing an attempt to restart the heart. CPR may extend a person's life and allow for more time with family or loved ones. Without CPR, the chances of living after cardiac arrest are slim to none.

\section{$\underline{\text { Section B }}$}

Section B provides three choices of medical care called Medical Interventions. The three levels are: Full Interventions, Limited Additional Interventions, and Comfort Measures.

\section{"Full Interventions"}


Full Interventions is the level of care all West Virginians will have if they have not completed a POST form or a do-not-resuscitate (DNR) order. Full Interventions include any treatments to keep the person alive. This level allows for the use of life support measures including a breathing machine and food and water through a feeding tube. Treatments also include care in the Intensive Care Unit (ICU).

\section{"What is ventilation and intubation?"}

A ventilator, or breathing machine, is a life support treatment that can be used if a person is not able to breathe on his or her own. A ventilator may be used when a patient is unconscious or if his or her lungs are not working. The machine pushes air into the lungs through a tube inserted in the windpipe. The tube is placed in a person's mouth, nose, or through a surgical hole in the neck.

"What are the risks of ventilation and intubation?"

The use of a breathing machine and attached tubes can result in damage to the lungs or airway about $10 \%$ of the time. The tube used to provide oxygen can damage the windpipe, vocal cords, lips, and teeth.

"What are the benefits of ventilation and intubation?"

A breathing machine can be helpful for patients who are having difficulty breathing due to a short-term illness or injury.

\section{"Limited Additional Interventions"}

Limited Additional Interventions provide basic medical treatments. This level of care includes the use of antibiotics, medications, and fluids injected into the vein. Life support measures, care in the ICU, and CPR will not be given if this level is chosen. Easily addressed treatments such as those for pneumonia or dehydration will be given.

\section{"Comfort Measures"}

Comfort Measures focus on patient comfort through symptom management. Medications, wound care, and other treatments are used to reduce pain and suffering. Comfort Measures do not have a goal to extend a patient's life with machines or medications. CPR will not be given if this level is chosen. People who choose Comfort Measures are more likely to die at home or where they live, than in the hospital, if that is their wish.

To review, Full Interventions are used when a patient prefers to be kept alive by any means. Patients with an order for Full Interventions can receive treatments such as: life support, ventilation, and intubation. Full Interventions is the default level of care for people living in West Virginia unless a POST form or DNR card is completed. Limited Additional Interventions include transfer to a hospital to receive basic and routine medical treatments. Patients with an order for this option prefer to avoid the ICU, life support treatments, and CPR. Comfort Measures focus on the relief of pain and suffering and do not include any life-prolonging treatments. Patients with a Comfort Measures order prefer to avoid life support measures and CPR.

\section{$\underline{\text { Section C }}$}


Section $\mathrm{C}$ provides choices for medically administered fluids and nutrition. The choices for fluids are: No IV fluids or IV fluids for a trial period. The choices for a feeding tube are: No feeding tube or feeding tube long-term.

\section{What are medically administered fluids?}

Fluids are given with an intravenous (IV) line that is placed under the skin into a vein. IV fluids can be provided to treat dehydration, for low blood pressure, or to patients who have difficulty swallowing. Antibiotics and pain medications can also be provided using an IV line. The process of inserting the IV line may cause mild pain or discomfort. To prevent skin irritation or infection, the IV insertion area is changed every 3-5 days.

\section{What are the risks of having medically administered fluids?}

Because the body becomes unable to use water and salt near the end of life, IV fluids can cause water build up or swelling in the legs, feet, stomach, and lungs. The fluids can cause pain in swollen body parts, nausea and vomiting, and breathing problems from congestion in the mouth and lungs.

\section{What is medically administered nutrition?}

A feeding tube can be used to provide nutrition to patients with injuries or diseases that make it difficult to swallow. It is often used on a temporary basis until the injury heals. Feeding tubes also can be used for people near end-of-life and those with end-stage diseases such as dementia. People with severe dementia often also have difficulty eating, forget to eat, or do not feel hungry.

A feeding tube is typically inserted in one of two ways: The first is through the nose, down the esophagus, and into the stomach known as a Nasograstric or NG tube. The second is through the skin into the stomach wall also known as a Gastrostomy or PEG tube. NG tubes are commonly used when nutrition is needed for a few days or weeks. A PEG tube is placed with surgery and is used when nutrition is needed for more than a few weeks.

\section{What are the risks of having medically administered nutrition?}

A feeding tube can cause aspiration, which is when food or liquids get into the lungs. Aspiration can often cause pneumonia, which can have significant impact on sick or elderly patients. Feeding tubes can also cause nausea or diarrhea (10\%) and minor infection or bleeding (10\%). NG tubes can cause discomfort and irritation and ulcers in the stomach. Patients with dementia may get upset and try to pull out the tube.

Long-term use of fluids or nutrition over months to years can be provided, but in most cases the treatments are not helpful in extending a patient's life or improving quality of life.

\section{What are the benefits of having medically administered fluids and nutrition?}

Medically administered fluids and nutrition can provide nutrients to patients who have lost the ability to swallow or have pain that makes it difficult to receive food by mouth.

Patients and their decision-makers are asked to consider the information in this video. Patients should also use their values, wishes, past experiences, and religious and spiritual beliefs to make decisions about what treatments they want near the end of life. Decision-makers should first 
consider what treatments the patient would want, based on previous discussions about patient values and wishes. If this information is not available, decision-makers should consider what treatments are in the best interests of the patient. 